\title{
LOS MODELOS DE REDUCCIÓN LÍTICA EN ALGETARES (ALGECIRAS, CÁDIZ) DURANTE EL MODO 2 Y SU CONTEXTUALIZACIÓN HISTÓRICA EN EL ÁMBITO DEL ESTRECHO DE GIBRALTAR
}

\section{The models of lithic reduction on the mode 2 in Algetares (Algeciras, Cádiz) ans his historical contextualization in the area of the Strait of Gibraltar}

\author{
Vicente Castañeda Fernández ${ }^{1}$, Luis Pérez Ramos ${ }^{2}$, Francisco Torres Abril², \\ Yolanda Costela Muñoz ${ }^{2}$, Rafael Jiménez-Camino Álvarez ${ }^{3}$ y José María \\ Tomassetti Guerra ${ }^{4}$
}

Recibido el 1 de julio de 2009. Aceptado el 28 de agosto de 2009.

Resumen. Este trabajo se centra en la excavación arqueológica desarrollada en el sitio paleolítico de Algetares (Algeciras, Cádiz), donde se analizan el depósito geológico, las materias primas empleadas, sus posibles áreas de captación y los modelos de fabricación de las herramientas de trabajo identificados de una forma tanto sincrónica como diacrónica. Finalmente, se procede a su contextualización en el ámbito del Estrecho de Gibraltar.

Palabras clave: Paleolítico, Estrecho de Gibraltar, Achelense, modo 2, Algeciras.

Summary. Our article focuses on the archaeological excavation developed in Algetares's palaeolithic site (Algeciras, Cadiz), where the geological deposit, raw materials, most likely captation areas and models of tool manufacture identified both synchronously and diachronically were analyzed. Finally, we proceed to contextualize it in the area of the Strait of Gibraltar.

Key Words: Palaeolithic, Estrecho de Gibraltar, Achelense, modo 2, Algeciras.

\section{NUESTRO PROGRAMA DE INVESTIGACIÓN}

Nuestros trabajos arqueológicos destinados a comprender el origen y desarrollo de las primeras sociedades del Paleolítico que habitaron en el extremo Sur de la Península Ibérica, y en concreto en el Campo de Gibraltar, se remontan al año $2001^{5}$. A partir de ese momento, hemos desarrollado diferentes campañas de prospección superficial (Castañeda, coord., 2008).

(1) Área de Prehistoria. Facultad de Filosofía y Letras. Universidad de Cádiz. e-mail: vicente.castaneda@uca.es

(2) Miembro del Grupo de Investigación Primeras ocupaciones humanas y sus inferencias socioeconómicas en el extremo Sur de la Península Ibérica (HUM-831).

(3) Arqueólogo Municipal. Ayuntamiento de Algeciras.

$\left({ }^{4}\right)$ Arqueotectura, S.L.L. Estudios de Patrimonio Arqueológico.

(5) En el año 2001 se nos aprobó un Proyecto de Investigación denominado Las bandas de cazadores-recolectores en el Campo de Gibraltar, autorizado y subvencionado por la Dirección General de Bienes Culturales de la Junta de Andalucía. Nuestro interés por la comarca, nos llevó a solicitar la creación del Grupo de Investigación denominado Primeras ocupaciones humanas y sus inferencias socioeconómicas en el extremo Sur de la Península Ibérica (HUM-831), que nos fue autorizado y subvencionado por la Consejería de Innovación, Ciencia y Empresa de la Junta de Andalucía en el año 2007. Ambos Programas de Investigación cuentan con la responsabilidad del Prof. Vicente Castañeda Fernández (Universidad de Cádiz). 
Nuestro interés por este territorio surgió, por un lado, como consecuencia de la información puntual obtenida gracias al estudio de los distintos yacimientos paleolíticos que se habían localizado a lo largo del siglo XX (Castañeda, 2001); mientras que por otro, tendríamos que mencionar su cercanía al continente africano, lugar donde se origina la Humanidad. Estos hechos convierten a esta comarca en un territorio estratégico para comprender, explicar y reflexionar sobre el origen del primer poblamiento humano localizado en el extremo Sur de la Península Ibérica.

Junto a los trabajos de prospección superficial, también hemos realizado y participado en diferentes campañas de excavación arqueológica desarrolladas sobre distintos yacimientos relacionados con el tecnocomplejo Achelense (modo
2), tales como El Lazareto (Castañeda, et al., 2005a), Cortijo de las Haciendas (Castañeda, et al., 2005b), o Algetares (Algeciras, Cádiz) (Castañeda, et al., e.p.).

El sitio de Algetares (Algeciras, Cádiz), tema central de este trabajo, fue objeto de una intervención arqueológica preventiva ${ }^{6}$ en el año 2008 (Jiménez-Camino, et al., 2008). Éste se localiza al extremo occidental de las Cordilleras Béticas, en el denominado Arco de Gibraltar (Martín Algarra, 1987) y sobre sedimentos del Surco Turbidítico (Ruiz-Reig, 1994). El sitio se halla en el T.M. de Algeciras (Cádiz) y ocupa un pequeño alto en la margen izquierda del río Pícaro, en las proximidades a su desembocadura en la Ensenada de Getares en la barriada de San García, al suroeste de la Bahía de Algeciras (Figura 1).

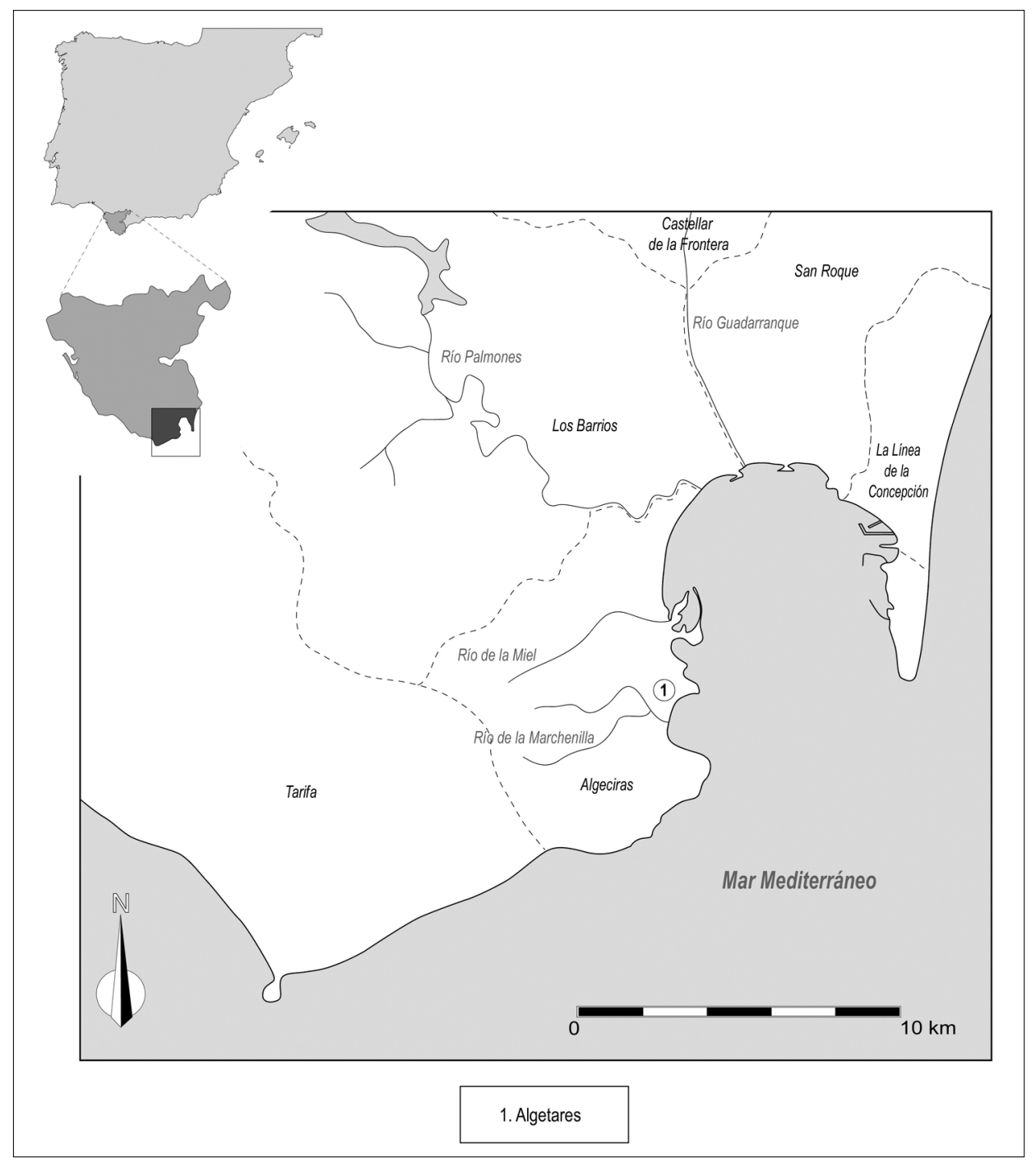

A FIgURA 1. Localización geográfica del sitio de Algetares (Algeciras, Cádiz).

(6) Este sitio fue identificado como consecuencia de una prospección superficial desarrollada en el ámbito de la Carta Arqueológica de Algeciras (Tomassetti, 2003a y 2003b). Los trabajos arqueológicos, realizados como consecuencia de las obras de construcción de un edificio de nueva planta, estuvieron a cargo de de la Fundación Municipal de Cultura "José Luis Cano", a través de su arqueólogo municipal, Rafael Jiménez Camino, y un arqueólogo especialista en prehistoria, José María Tomassetti. Un acuerdo entre el Departamento de Arqueología de Algeciras y nuestro grupo de investigación, permitió la colaboración científica tanto en los trabajos de excavación como los posteriores de estudio de los materiales arqueológicos. 
La localización geográfica de este sitio en el Campo de Gibraltar, la comarca más meridional de la Península lbérica, única bañada por el Océano Atlántico y el Mar Mediterráneo, y situada en el extremo occidental de las Cordilleras Béticas, le confiere ciertas características medioambientales e históricas únicas.

Estos trabajos arqueológicos desarrollados en el extremo Sur de la Península lbérica nos están permitiendo profundizar en el primer poblamiento humano desarrollado en la comarca del Campo de Gibraltar, y al mismo tiempo, el ir perfilando nuestro modelo de contrastación histórico ${ }^{7}$, aún en construcción, y contextualizado en el ámbito del Estrecho de Gibraltar (Castañeda, coord., 2008).

Las características del sitio de Algetares, que no han permitido la conservación de materia orgánica como consecuencia del tipo de sedimento donde se localiza, limitan nuestras inferencias históricas, aunque nos permite, por una parte, profundizar de una forma parcial en el análisis de los procesos técnicos de fabricación de las herramientas de trabajo realizadas sobre rocas e identificadas en las distintas unidades estratigráficas; mientras que por otro, nos aproxima a la articulación social del territorio por parte de estas primeras sociedades del Paleolítico y su contextualización en el ámbito del Estrecho de Gibraltar. Por otra parte, aunque el sitio de Algetares no cuenta hasta la fecha con dataciones absolutas, si podemos correlacionar su deposito con otras formaciones geológicas existentes en el entorno inmediato (terrazas fluviales y marinas), contando algunas de ellas con fechaciones absolutas.

\section{EL PROCESO DE EXCAVACIÓN ARQUEOLÓGICA}

La excavación arqueológica desarrollada en el sitio de Algetares presentaba como objetivos generales su contextualización geomorfológica, su delimitación espacial y su definición cronoestratigráfica, presentando como objetivo central la creación de un modelo contrastable y su contextualización en las primeras sociedades del Paleolítico que habitaron en el ámbito del Estrecho de Gibraltar (Lámina 1).

Para alcanzar estos objetivos, se proyectaron varias fases de investigación. En primer lugar se realizó una prospección superficial, a través del cual se pudo identificar el perfil que, a principios de la primera década del siglo XXI, permitió la localización del sitio arqueológico. Posteriormente, una vez documentadas las áreas más representativas, se procedió a la realización de 3 sondeos de $3 \times 3 m(A, B$ y $C)$ y cuatro zanjas valorativas de 9,47 x $1 \mathrm{~m}$ (D), 10x1 $\mathrm{m}$ (E), 15,10 x $1 \mathrm{~m}$ (F) y $5,61 \times 1 \mathrm{~m}(\mathrm{G})$, que permitió delimitar con precisión el yacimiento. Una vez terminados estos trabajos, se planteó una excavación en extensión de $9 \times 7,5 \mathrm{~m}$ (Sondeo EN, siglas de "extensión norte") que englobó al Sondeo $C$, el único con secuencia arqueológica positiva, y que a partir de este momento pasó a denominarse Sector C (Figura 2).

El Sondeo EN quedó dividido en nueve cuadrículas, de las cuales las identificadas entre las letras A y $F$, otorgadas empezando por la esquina SO de izquierda a derecha y de sur a norte, presentan unas dimensiones de $3 \times 3 \mathrm{~m}$, mientras que las designadas con las letras $\mathrm{G}, \mathrm{H}$ e I se relacionan con

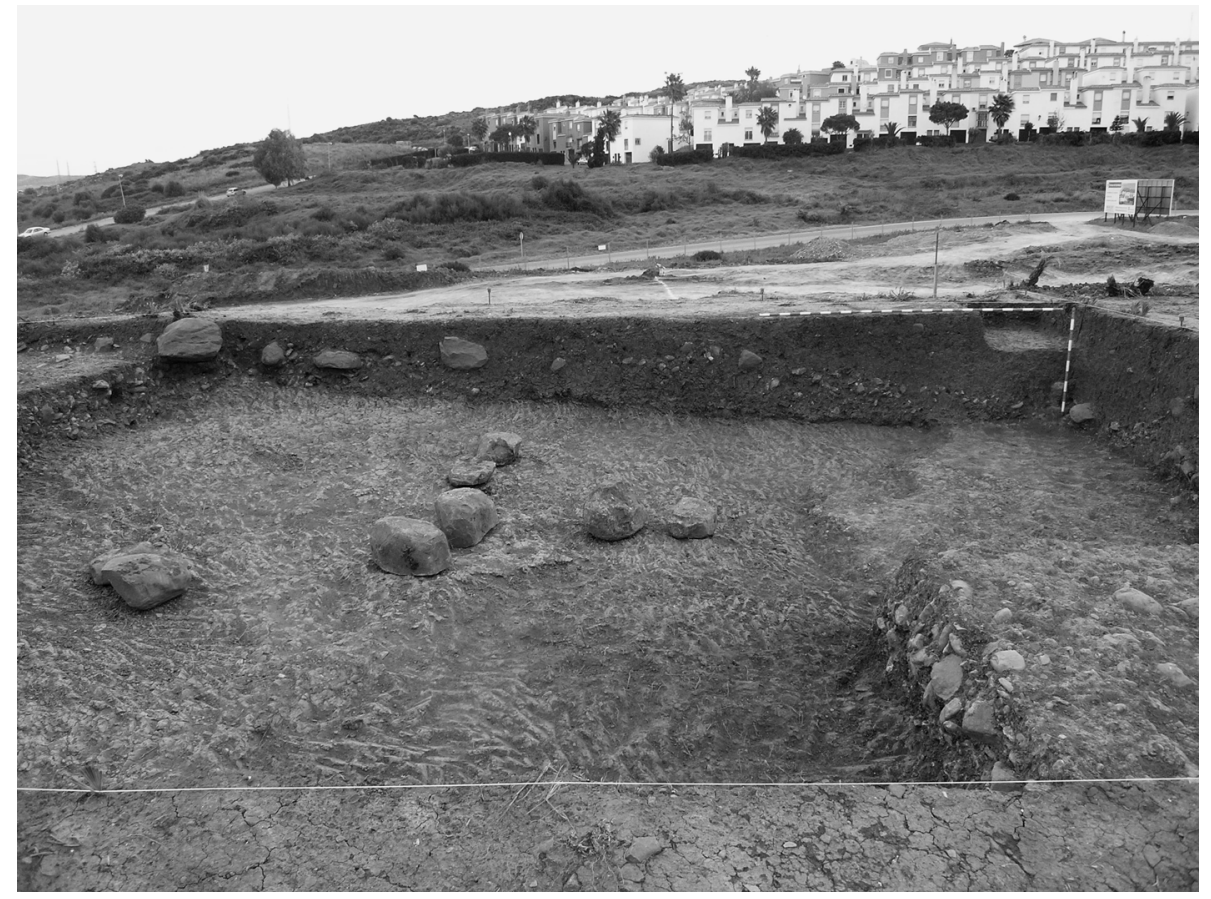

- LÁmina 1. Vista general del sitio de Algetares (Algeciras, Cádiz).

(7) Este proyecto parte de una propuesta teórica y metodológica crítica con la Historia, y que ya ha sido explicada en otros trabajos (Castañeda, et al., 2005a). 


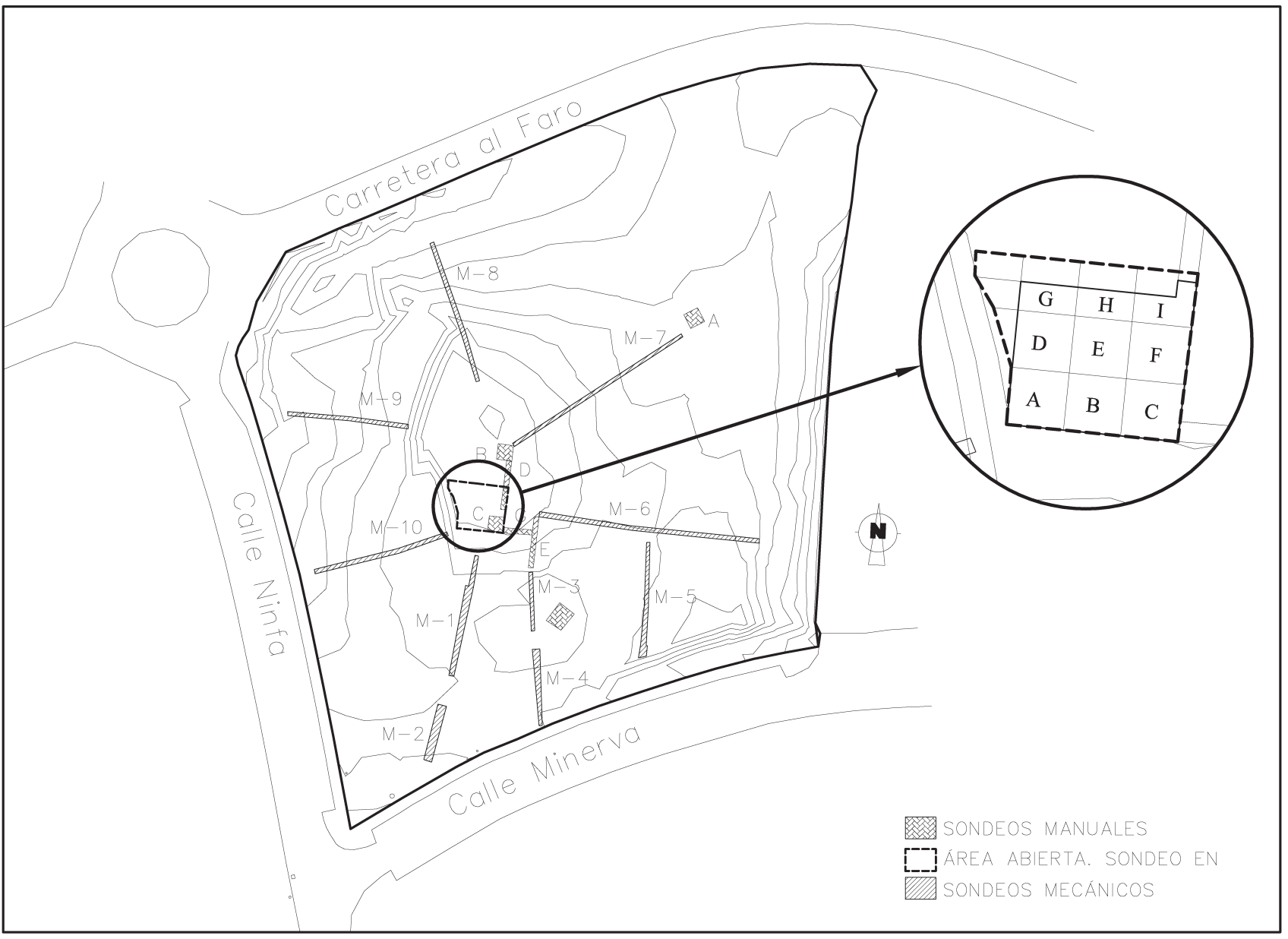

A Figura 2. Cortes estratigráficos planteados en el sitio de Algetares (Algeciras, Cádiz).

unas dimensiones de $3 \times 1,5 \mathrm{~m}$. El menor tamaño de estas cuadrículas es consecuencia del retranqueo del perfil Norte dada la escasez de hallazgos en este lugar con la intención de mantener un perfil estratigráfico.

La excavación arqueológica del Sondeo EN ha permitido diferenciar cinco unidades estratigráficas, de las cuales para este estudio se han desestimado las UE1, al encontrarse la industria lítica descontextualizada como consecuencia de la erosión de las unidades subyacentes y la presencia de indicadores culturales de época contemporánea, y la UE5, identificada tan sólo en la esquina SE, bajo la UE3 y sobre la UE4, y un conjunto material muy reducido (Lámina 2).

\section{GEOLOGÍA Y GEOMORFOLOGÍA}

La Ensenada de Getares, lugar donde se localiza este sitio arqueológico, está excavada sobre un conjunto de materiales lutíticos de las Unidades de Almarchal y Algeciras en sus facies más arcillosas, rodeados por materiales más competentes (megaturbiditas de la Unidad de Algeciras y Arenisca del Aljibe) que conforman los relieves adyacentes y que han

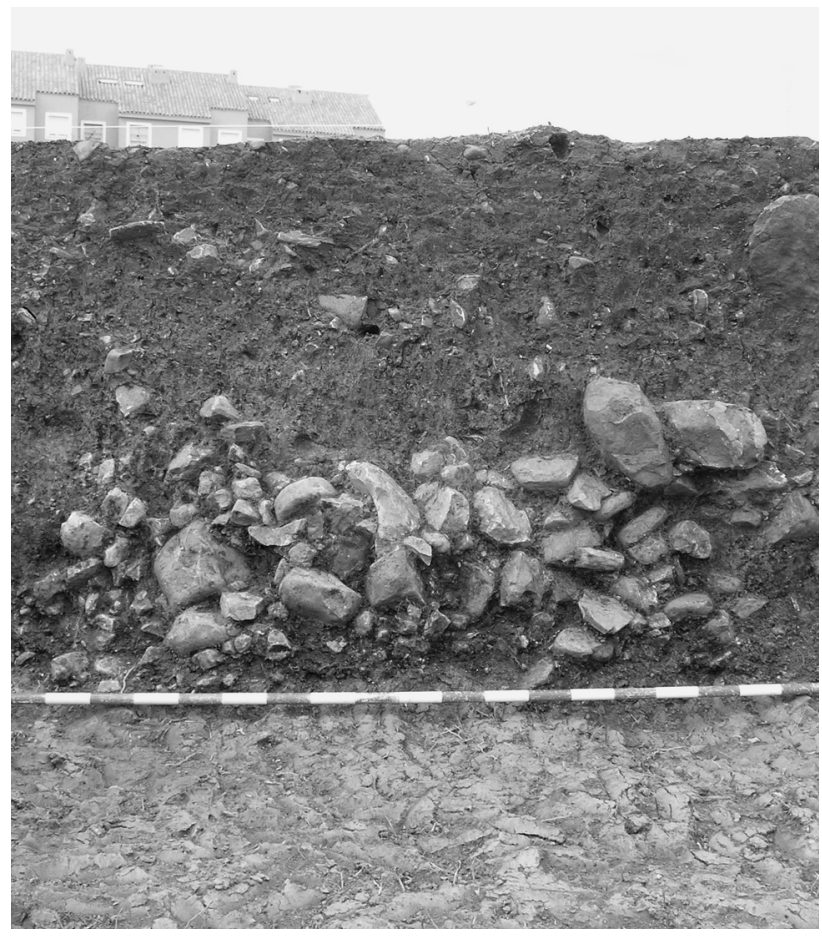

A LÁmina 2. Estratigrafía. Perfil Sur. 
actuado como zonas de captación de caudales hídricos y área fuente de derrubios.

Durante el Cuaternario, debido a causas tectónicas y climáticas, sobre los materiales cretácicos y terciarios del Surco turbidítico se fueron escalonando una serie de depósitos y superficies estructurales, continentales y marinas: deslizamientos de ladera, depósitos fluviales, dunas fósiles, glacis erosivos, rasas, etc. (Castañeda, et al., e.p.), junto con el glacis deposicional en el que se localiza el sitio de Algetares.

Los depósitos fluviales de la zona se estructuran en forma de terrazas $a+41,+23 y+17$ m.s.n.m. La más alta se correspondería con la terraza superior, o "Terraza Lazareto", definida por el cercano rio Palmones (Torres, 2008), mientras que las situadas a cotas +23 y $+17 \mathrm{~m}$. serían equiparables a la terraza media o "Terraza Chaparral" del mismo río, para la que se propone la edad Pleistoceno medio, en sentido amplio (Hernaiz, et al., 1991a).

El sitio de Algetares se situa a cota +36 m., en un pequeño cerro de margas y arcillas pertenecientes a la Unidad Almarchal. Sobre estos materiales del Surco Turbiditico, y mediante una superficie erosiva irregular, aflora una cuña, de poco más de 1 metro de espesor, donde se localiza el material arqueológico. Consiste en un conglomerado muy heterométrico, soportado por la matriz, con cantos y bloques mayoritariamente de Arenisca del Aljibe y una matriz arciIloso-limoso-arenosa de colores rojos, marrones y verdes. Los cantos son de esfericidad baja-media y van de muy angulosos a subredondeados, abundando los cantos y bloques poco competentes, que se desmoronan por falta de cementación, lo que indicaría un transporte relativamente corto.

En este paquete conglomerático hemos distinguido, de techo a muro (Figura 3):

- Nivel edáfico (UE1). Capa irregular, muy humificada, de unos 10 centímetros de espesor máximo, de arenas marrones masivas con algunos cantos dispersos de pequeño tamaño.

- Conglomerado superior. Incluye las unidades estratigráficas UE2, UE3 y UE5. Es un nivel de unos 50-70 centímetros de arenas limosas marrón-rojizas con cantos, en su mayor parte de Arenisca del Aljibe. Los cantos presentan un tamaño y un índice de redondeamiento menor que en el nivel infrayacente, además de mostrar cierto grado de alteración con córtex y pátinas rojizas. La matriz muestra bioturbación por raíces y rubefacción por percolación de agua superficial. La unidad estratigráfica UE5, caracterizada por presentar una matriz más arcillosa y escasa presencia de cantos, la interpretamos como depositada por fenómenos de deslizamiento de ladera, tipo "colada de barro".

- Conglomerado inferior (UE4). Depósito con grandes variaciones laterales de potencia debido a su irregular muro erosivo. Se trata de un conglomerado soportado por la matriz con cantos que llegan a los 60 centímetros de diámetro y que no presentan pátina ni córtex, aunque sí algunas manchas de color negro. La matriz es de arena arcillosa de color verde y sin rubefacción, aunque con mineralizaciones negruzcas, probablemente de oxihidróxidos de hierro y manganeso, originadas por percolación a través de conductos debidos a bioturbación por raíces.

Tanto en el seno del nivel conglomerático inferior como en el superior (UE2, UE3 y UE4) hemos identificado lo que se ha denominado "cantos rodados erosionados", que implican la exposición de los mismos a la intemperie, una vez depositados, durante prolongados periodos de tiempo, en los que predominaría la erosión sin depósito. Esto conlleva, dentro de cada paquete conglomerático, momentos pun-

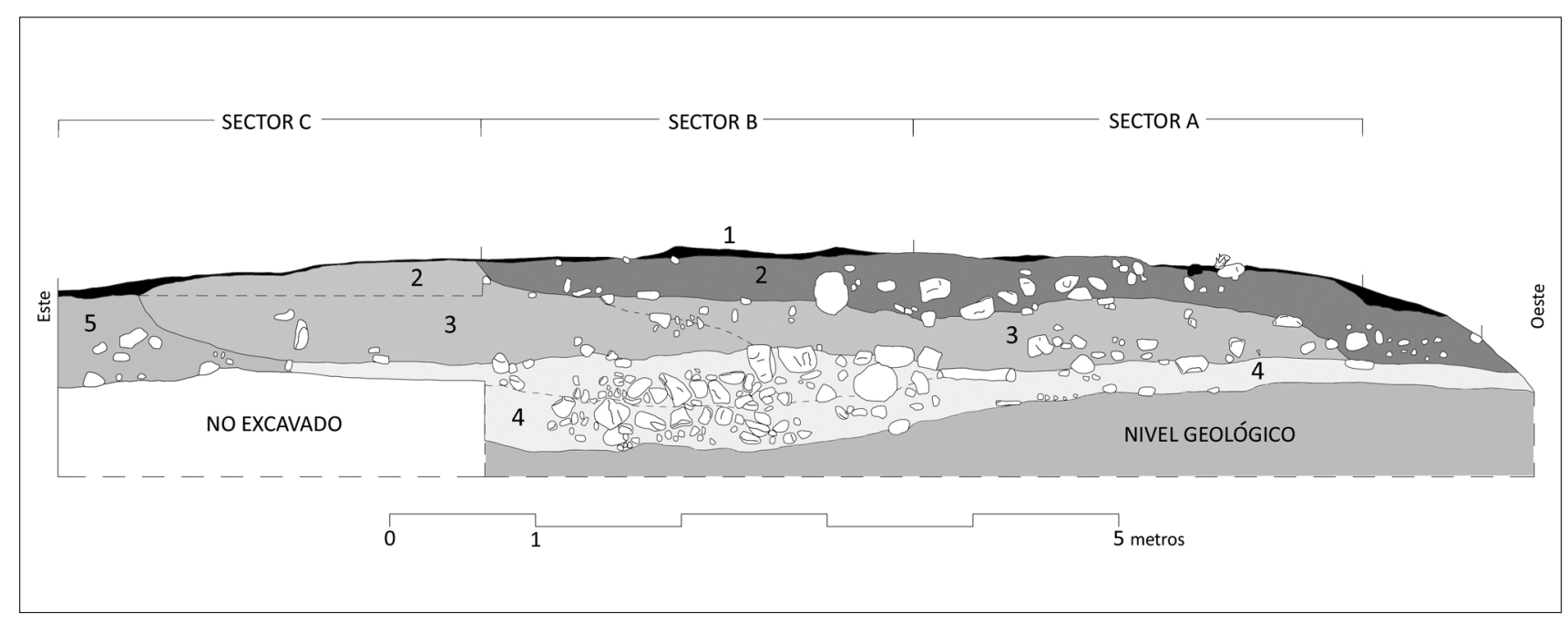

- Figura 3. Estratigrafía. Perfil Sur. 
tuales de aluvionamiento separados por largos periodos erosivos.

Todo lo anterior indica, para las unidades estratigráficas UE2, UE3 y UE4 un transporte corto y rápido, con predominio de corrientes densas y viscosas, lo que nos lleva a proponer un origen aluvial. Habría que hablar de, al menos, dos épocas principales de aluvionamiento, correspondientes a cada uno de los niveles conglomeráticos.

Con respecto a la datación relativa de estos materiales, aunque las relaciones espaciales con los otros depósitos cuaternarios no son claras, y teniendo en cuenta su aparente posición intermedia entre la terraza fluvial tipo Lazareto y la tipo Chaparral, habría que atribuirles una edad Pleistoceno Medio en sentido amplio.

\section{MATERIAS PRIMAS, ÁREAS DE CAPTACIÓN Y PROCESOS DE SELECCIÓN.}

Dentro de los estudios geoarqueológicos llevados a cabo en el sitio de Algetares, se ha realizado la caracterización mineralógica y petrológica a visu de toda la industria lítica, a fin de determinar los diferentes tipos litológicos. En una segunda fase, hemos comparado estos datos con la litología que aflora en la zona, a fin de identificar posibles áreas fuentes de aprovisionamiento de materias primas líticas, tanto autóctonas como alóctonas.

La práctica totalidad $(98,5 \%)$ de los restos líticos analizados se han elaborado a partir de Arenisca del Aljibe (Gavala, 1924; Pendon, 1978), siendo el resto sílex, cuarcita y caliza. A su vez, este tipo de arenisca es la roca más utilizada en las industrias líticas relacionadas con el modo 2 en el Campo de Gibraltar (Domínguez-Bella, 2008). Afloran, por lo general, en gruesos paquetes con el interior poco cementado y con una costra superficial endurecida por óxidos de hierro, exudados desde el interior, que los protege de la erosión (Torres, 2008). Sin embargo, existen otros estratos intensamente cementados por la sílice removilizada de la propia arenisca, lo que les confiere compacidad y la propiedad de producir filos cortantes al ser fracturados. Es este tipo de Arenisca del Aljibe, muy cementada por sílice, la materia prima mineral utilizada mayoritariamente en el sitio de Algetares.

En la distribución porcentual de litologías para el total de los restos materiales líticos, estudiados hasta el momento (Figura 4), se observa mayor abundancia de areniscas de grano medio $(44,1 \%)$ y grueso $(26,3 \%)$, seguidas de las de grano fino (18,3\%), siendo minoritarias las de grano muy fino y muy grueso (4,9\% cada una). Este hecho podría explicarse por la mayor proporción del grano medio y grueso en el conjunto de la Unidad de Aljibe y, por tanto, en los sedimentos originados por su erosión, pero también nos lleva a proponer que el principal criterio de selección de materias primas líticas, para esta época, no era el tamaño de grano (en teoría, cuanto más fino, más homogéneas e isótropas serian estas rocas, luego más fáciles y "precisas" de tallar), sino que sería el grado de cementación por sílice, ya que, a mayor cementación, mayor dureza, resistencia y más capacidad para producir filos cortantes ante los procesos de talla.

Proponemos un probable origen local para todas las materias primas minerales utilizadas en el sitio de Algetares. En el caso de la arenisca, la fuente más factible serian los cantos rodados procedentes de la erosión de los relieves de Arenisca del Aljibe circundantes, tanto los de origen aluvial,

\section{Unidad estratigráfica 2}

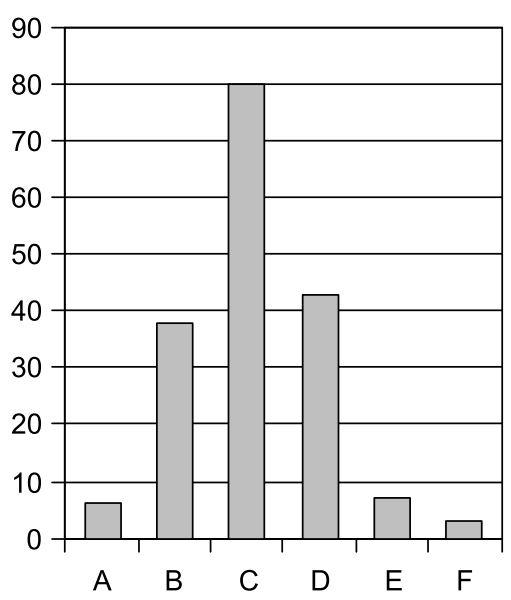

Unidad estratigráfica 3

Unidad estratigráfica 4

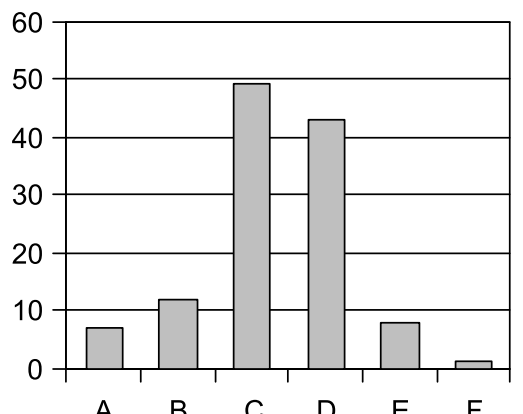

FiguRa 4. Distribución de tipos litológicos por unidades estratigráficas (en coordenadas se representa el número de productos líticos. A: Arenisca de grano muy fino, B: Arenisca de grano fino, C: Arenisca de grano medio, D: Arenisca de grano grueso, E: Arenisca de grano muy grueso, F: Otros (sílex, cuarcita y caliza). 
pertenecientes al glacis donde se localiza el propio yacimiento, como los de origen fluvial, de las cercanas terrazas fluviales del río Pícaro, ya que el transporte acuoso que han sufrido selecciona los cantos más cementados y compactos, deshaciendo los menos cementados durante el mismo. En este sentido, hay que tener en cuenta que la ensenada de Getares está constituida mayoritariamente por sedimentos pertenecientes a la Unidad de Algeciras, donde los estratos areniscosos son eminentemente calcáreos. Los depósitos aluviales y fluviales cuaternarios, discordantes sobre los sedimentos terciarios del Surco Turbidítico de la ensenada de Getares, aportaron material siliceo, potencialmente tallable, a una zona donde éste escaseaba, pero rica en recursos, por la cercanía a la desembocadura del paleo-Pícaro en la Bahía de Algeciras. Este hecho explicaría la intensa utilización de estos recursos líticos siliceos, como pone de manifiesto el alto porcentaje de cantos y bloques de arenisca tallados en el yacimiento.

En cuanto al sílex, muy minoritario en los depósitos fluvio-aluviales de la zona, y escaso en la comarca, tres de las piezas fabricadas en este tipo de roca son claramente asimilables a afloramientos terciarios, tipo Cerro de Agua de Enmedio (Torres, et al., 2002), asociados a las series basales de la Unidad del Aljibe, mientras que la cuarta, elaborada en sílex de facies subbéticas, tendría su posible área fuente más cercana en el afloramiento penibético de los Pastores, próximo al yacimiento. Este afloramiento es también la procedencia más probable de la BP elaborada en caliza hallada hasta el momento. Para la BN2G de cuarcita, único producto arqueológico fabricado con material no sedimentario, proponemos una procedencia también autóctona: los sedimentos de las terrazas marinas de la zona, donde solamente se localiza material metamórfico en toda la comarca, y en los que abundan los cantos de cuarzo lechoso y metacuarcita.

\section{MODELOS DE REDUCCIÓN LÍTICA Y CONFIGURACIÓN DE LAS HERRAMIENTAS DE TRABAJO}

Los objetos líticos son las únicas evidencias arqueológicas recuperadas en el sitio de Algetares. Para su análisis hemos aplicado el Sistema Lógico Analítico (SLA) (Carbonell, Guilbaud y Mora 1983; Carbonell, et al., 1992), al considerarlo el más adecuado con nuestra propuesta teórica de partida y a este tipo de conjuntos, fundamentalmente por lo que supone de ruptura con los subjetivos, empíricos y cerrados sistemas de clasificación tipológicos tradicionales (Carbonell, et al., 2006), por la lectura analítica (Laplace, 1972; Clarke, 1984), sistémica (Clarke,. 1984) y procesual que realiza del registro y por introducir los factores espacio y tiempo en el análisis de los objetos (Carbonell, et al., 1997), al que incorporamos algunas de las matizaciones y aportaciones que al mismo realizan en sus respectivas tesis doctorales diferentes autores (Mosquera, 1995; Rodríguez, 1997; Garcia, 2005).

Siguiendo el esquema de categorías de conceptos del SLA, que parten de lo concreto hacia lo general, cada artefacto ha sido clasificado e integrado en la Categoría Estructural correspondiente, situándolo así de manera espacio-temporal en el momento que le corresponde dentro de la secuencia de producción.

Los materiales objeto de análisis para este trabajo se corresponden con una muestra de aproximadamente el 50\% del total, encontrándose el resto en la actualidad en estudio.

El registro litotécnico lo componen un total de 407 productos, repartidos por unidades estratigráficas de la siguiente manera: la UE2 con 166 artefactos, compuesta por 45 BN1G $(27,1 \%), 100 \mathrm{BP}(60,2 \%)$ y $21 \mathrm{BN} 2 \mathrm{G}(12,7 \%)$; la UE3 con un total de 127 objetos, que se reparten por Categorías Estructurales de la siguiente manera: 31 BN1G $(24,4 \%), 82$ BP $(64,6 \%)$ y 14 BN2G $(11 \%)$ y, finalmente, la UE4 con un total de 114 piezas, documentándose 28 BN1G (24,6\%), 68 BP $(59,6 \%)$ y 18 BN2G $(15,8 \%)$.

La materia prima empleada en la explotación y configuración de los objetos líticos en la UE2 supone el dominio de la arenisca con un 100\% en las BN1G, el 98\% de las BP y el $90,5 \%$ de las BN2G, mientras que el $2 \%$ de BP y el $9,5 \%$ de $B N 2 G$ están realizadas en otras materias primas. En la UE3 se ha empleado la arenisca en un $99,2 \%$ y otras materias primas en el 0,8\% de BN2GC. De los 113 artefactos de la UE4, la arenisca ha sido utilizada en un 99,1\%, estando presente el empleo de otras materias primas en el 0,9\% de las BN2GC. Estas materias primas, como ya se indicó, son de origen local, localizándose de manera natural en el propio sitio arqueológico, por lo que su aprovisionamiento ha sido inmediato, observándose una selección de la arenisca compacta y bien cementada, que en el proceso de talla permite la obtención de filos diedros activos, empleándose como segundo tipo de roca en proporciones ínfimas el sílex para la configuración de BN2GC.

El estudio del rodamiento nos arroja unos índices entre el grado medio y poco del $92,2 \%$ en la UE2, del $78 \%$ en la UE3 y del 88,6 en la UE4, estando por ello escasamente representado el grado bastante, lo que nos informa de las escasas alteraciones postdeposicionales sufridas por el material. Esta información coincide con la obtenida del estudio geológico y geomorfológico.

El análisis de las diferentes Categorías Estructurales, nos ha permitido diferenciar la presencia de Bases Negativas de Primera Generación (BN1G), Bases Positivas (BP) y Bases Negativas de Segunda Generación (BN2G).

Las BN1G (Tablas 1 a 3) que son el resultado de la interacción de dos bases naturales, han sido divididas, según se correspondan con una secuencia de configuración (BN1GC) o de explotación (BN1GE) (Figura 5). 


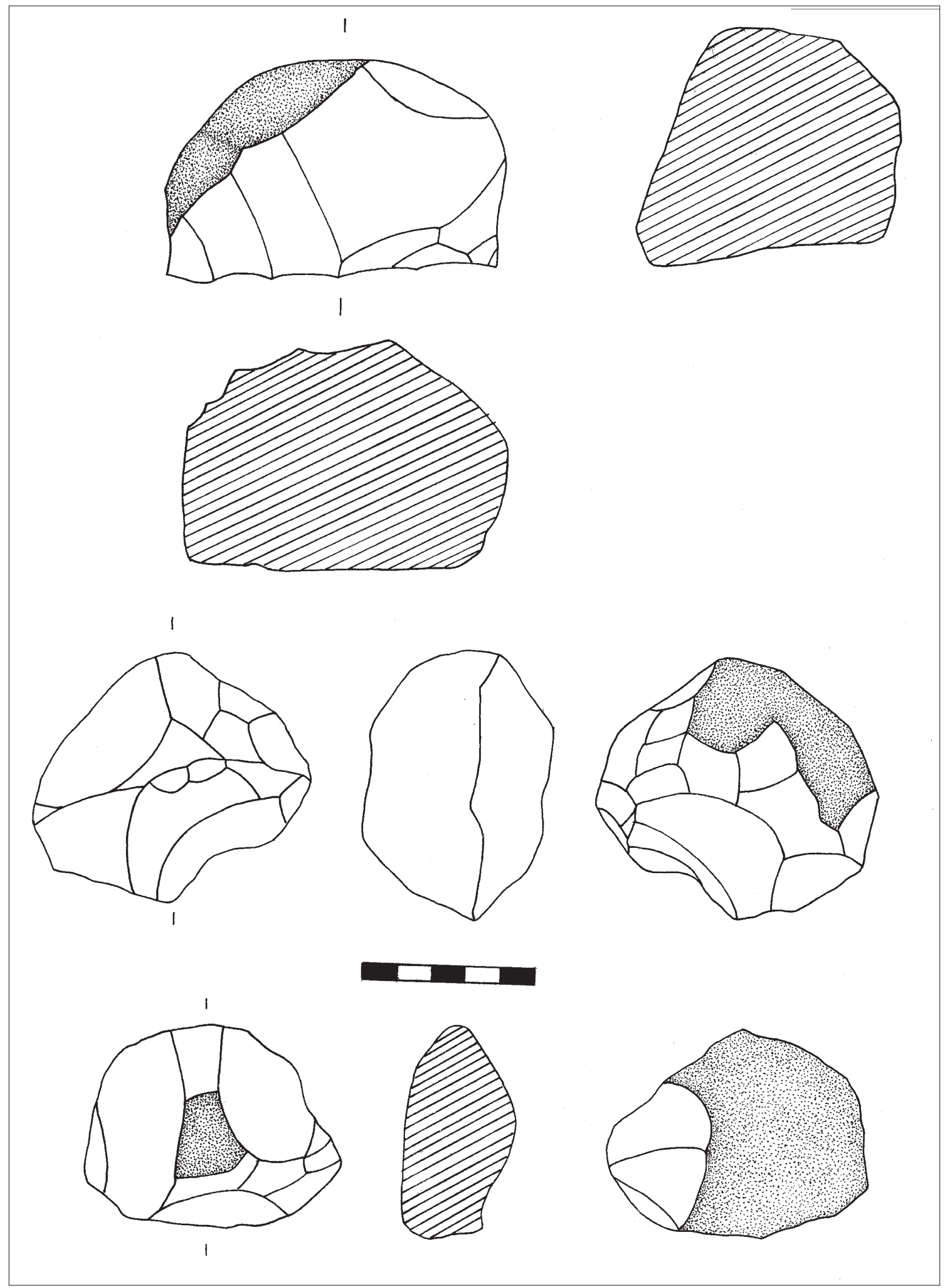

A FiguRA 5. Algetares. UE2. BN1GE: longitudinal (1), predetermnado parcial (2) y centrípeto sin preparación (3).

○ UNED. Espacio, Tiempo y Forma. Serie I, Nueva época. Prehistoria y Arqueología, t. 2, 2009. 
Tabla 1. Análisis morfotécnico de las BN1G de la UE2

\begin{tabular}{|c|c|c|c|c|c|c|c|c|c|c|}
\hline \multirow{3}{*}{ Criterios analíticos } & \multicolumn{8}{|c|}{ Facialidad BN1G } & \multirow{2}{*}{\multicolumn{2}{|c|}{$\begin{array}{c}\text { Total caras } \\
\text { talladas BN1G }\end{array}$}} \\
\hline & \multicolumn{2}{|c|}{ Unifacial } & \multicolumn{2}{|c|}{ Bifacial } & \multicolumn{2}{|c|}{ Trifacial } & \multicolumn{2}{|c|}{ Multifacial } & & \\
\hline & N. ${ }^{\circ}$ & $\%$ & N. ${ }^{\circ}$ & $\%$ & $\mathrm{~N} .^{\circ}$ & $\%$ & N. ${ }^{\circ}$ & $\%$ & N. ${ }^{\circ}$ & $\%$ \\
\hline \multicolumn{11}{|l|}{ Carácter centrípeto } \\
\hline $1 \mathrm{C}$ & 4 & 80,0 & 1 & 20,0 & 0 & 0,0 & 0 & 0,0 & 5 & 7,9 \\
\hline $2 \mathrm{C}$ & 11 & 78,6 & 3 & 21,4 & 0 & 0,0 & 0 & 0,0 & 14 & 22,2 \\
\hline $3 \mathrm{C}$ & 8 & 53,3 & 5 & 33,3 & 0 & 0,0 & 2 & 13,3 & 15 & 23,8 \\
\hline $4 \mathrm{C}$ & 6 & 20,7 & 1 & 44,8 & 6 & 20,7 & 4 & 13,8 & 29 & 46,0 \\
\hline Total & 29 & 46,0 & 22 & 34,9 & 6 & 9,5 & 6 & 9,5 & 63 & 100,0 \\
\hline \multicolumn{11}{|l|}{ Carácter de oblicuidad } \\
\hline Plano & 3 & 16,7 & 9 & 50,0 & 3 & 16,7 & 3 & 16,7 & 18 & 28,6 \\
\hline Semiplano & 2 & 33,3 & 2 & 33,3 & 1 & 16,7 & 1 & 16,7 & 6 & 9,5 \\
\hline Simple & 8 & 40,0 & 9 & 45,0 & 1 & 5,0 & 2 & 10,0 & 20 & 31,7 \\
\hline Semiabrupto & 3 & 50,0 & 2 & 33,3 & 1 & 16,7 & 0 & 0,0 & 6 & 9,5 \\
\hline Abrupto & 13 & 100,0 & 0 & 0,0 & 0 & 0,0 & 0 & 0,0 & 13 & 20,6 \\
\hline Total & 29 & 46,0 & 22 & 34,9 & 6 & 9,5 & 6 & 9,5 & 63 & 100,0 \\
\hline \multicolumn{11}{|l|}{ Profundidad del retoque } \\
\hline Marginal & 7 & 87,5 & 1 & 112,5 & 0 & 0,0 & 0 & 0,0 & 8 & 12,7 \\
\hline Profundo & 13 & 86,7 & 2 & 13,3 & 0 & 0,0 & 0 & 0,0 & 15 & 23,8 \\
\hline Muy profundo & 3 & 25,0 & 7 & 58,3 & 1 & 8,3 & 1 & 8,3 & 12 & 19,0 \\
\hline Profundidad total & 6 & 21,4 & 12 & 42,9 & 5 & 17,9 & 5 & 17,9 & 28 & 44,4 \\
\hline Total & 29 & 46,0 & 22 & 34,9 & 6 & 9,5 & 6 & 9,5 & 63 & 100,0 \\
\hline \multicolumn{11}{|l|}{ Arista frontal } \\
\hline Convexa & 19 & 45,2 & 17 & 40,5 & 4 & 9,5 & 2 & 4,8 & 42 & 66,7 \\
\hline Recta & 10 & 50,0 & 4 & 20,0 & 2 & 10,0 & 4 & 20,0 & 20 & 31,7 \\
\hline Cóncava & 0 & 0,0 & 1 & 100,0 & 0 & 0,0 & 0 & 0,0 & 1 & 1,6 \\
\hline Total & 29 & 46,0 & 22 & 34,9 & 6 & 9,5 & 6 & 9,5 & 63 & 100,0 \\
\hline \multicolumn{11}{|l|}{ Arista sagital } \\
\hline Recta & 14 & 45,2 & 10 & 32,3 & 4 & 12,9 & 3 & 9,7 & 31 & 49,2 \\
\hline Incurvada & 15 & 53,6 & 8 & 28,6 & 2 & 7,1 & 3 & 10,7 & 28 & 44,4 \\
\hline Sinuosa & 0 & 0,0 & 4 & 100,0 & 0 & 0,0 & 0 & 0,0 & 4 & 6,3 \\
\hline Total & 29 & 46,0 & 22 & 34,9 & 6 & 9,5 & 6 & 9,5 & 63 & 100,0 \\
\hline \multicolumn{11}{|l|}{ Simetría arista sagital } \\
\hline Simétrica & 6 & 35,3 & 9 & 52,9 & 0 & 0,0 & 2 & 11,8 & 17 & 27,0 \\
\hline Asimétrica & 23 & 50,0 & 13 & 28,3 & 6 & 13,0 & 4 & 8,7 & 46 & 73,0 \\
\hline Total & 29 & 46,0 & 22 & 34,9 & 6 & 9,5 & 6 & 9,5 & 63 & 100,0 \\
\hline
\end{tabular}


Tabla 2. Análisis morfotécnico de las BN1G de la UE3

\begin{tabular}{|c|c|c|c|c|c|c|c|c|}
\hline \multirow{3}{*}{ Criterios analíticos } & \multicolumn{6}{|c|}{ Facialidad BN1GE } & \multirow{2}{*}{\multicolumn{2}{|c|}{$\begin{array}{c}\text { Total caras } \\
\text { talladas }\end{array}$}} \\
\hline & \multicolumn{2}{|c|}{ Unifacial } & \multicolumn{2}{|c|}{ Bifacial } & \multicolumn{2}{|c|}{ Trifacial } & & \\
\hline & $\mathrm{N} .{ }^{\circ}$ & $\%$ & N. ${ }^{\circ}$ & $\%$ & $\mathrm{~N} .{ }^{\circ}$ & $\%$ & $\mathrm{~N} .^{\circ}$ & $\%$ \\
\hline \multicolumn{9}{|l|}{ Carácter centrípeto } \\
\hline NC & 1 & 50,0 & 1 & 50,0 & 0 & 0,0 & 2 & 4,1 \\
\hline $1 \mathrm{C}$ & 2 & 66,7 & 1 & 33,3 & 0 & 0,0 & 3 & 6,1 \\
\hline $2 \mathrm{C}$ & 3 & 42,9 & 4 & 57,1 & 0 & 0,0 & 7 & 14,3 \\
\hline $3 C$ & 2 & 28,6 & 4 & 57,1 & 1 & 14,3 & 7 & 14,3 \\
\hline $4 C$ & 10 & 33,3 & 6 & 20,0 & 14 & 46,7 & 30 & 61,2 \\
\hline Total & 18 & 36,7 & 16 & 32,7 & 15 & 30,6 & 49 & 100,0 \\
\hline \multicolumn{9}{|l|}{ Carácter de oblicuidad } \\
\hline Plano & 9 & 37,5 & 5 & 20,8 & 10 & 41,7 & 24 & 49,0 \\
\hline Semiplano & 4 & 57,1 & 2 & 28,6 & 1 & 14,3 & 7 & 14,3 \\
\hline Simple & 4 & 30,8 & 5 & 38,5 & 4 & 30,8 & 13 & 26,5 \\
\hline Semiabrupto & 0 & 0,0 & 2 & 100,0 & 0 & 0,0 & 2 & 4,1 \\
\hline Abrupto & 1 & 33,3 & 2 & 66,7 & 0 & 0,0 & 3 & 6,1 \\
\hline Total & 18 & 36,7 & 16 & 32,7 & 15 & 30,6 & 49 & 100,0 \\
\hline \multicolumn{9}{|l|}{ Profundidad del retoque } \\
\hline Marginal & 2 & 66,7 & 1 & 33,3 & 0 & 0,0 & 3 & 6,1 \\
\hline Profundo & 1 & 16,7 & 5 & 83,3 & 0 & 0,0 & 6 & 12,2 \\
\hline Muy profundo & 6 & 50,0 & 4 & 33,3 & 2 & 16,7 & 12 & 24,5 \\
\hline Profundidad total & 9 & 32,1 & 6 & 21,4 & 13 & 46,4 & 28 & 57,1 \\
\hline Total & 18 & 36,7 & 16 & 32,7 & 15 & 30,6 & 49 & 100,0 \\
\hline \multicolumn{9}{|l|}{ Arista frontal } \\
\hline Convexa & 8 & 33,3 & 8 & 33,3 & 8 & 33,3 & 24 & 49,0 \\
\hline Recta & 8 & 36,4 & 7 & 31,8 & 7 & 31,8 & 22 & 44,9 \\
\hline Cóncava & 2 & 66,7 & 1 & 33,3 & 0 & 0,0 & 3 & 6,1 \\
\hline Total & 18 & 36,7 & 16 & 32,7 & 15 & 30,6 & 49 & 100,0 \\
\hline \multicolumn{9}{|l|}{ Arista sagital } \\
\hline Recta & 9 & 34,6 & 8 & 30,8 & 9 & 34,6 & 26 & 53,1 \\
\hline Incurvada & 9 & 50,0 & 5 & 27,8 & 4 & 22,2 & 18 & 36,7 \\
\hline Sinuosa & 0 & 0,0 & 3 & 60,0 & 2 & 40,0 & 5 & 10,2 \\
\hline Total & 18 & 36,7 & 16 & 32,7 & 15 & 30,6 & 49 & 100,0 \\
\hline \multicolumn{9}{|l|}{ Simetría arista sagital } \\
\hline Simétrica & 1 & 16,7 & 2 & 33,3 & 3 & 50,0 & 6 & 12,2 \\
\hline Asimétrica & 17 & 39,5 & 14 & 32,6 & 12 & 27,9 & 43 & 87,8 \\
\hline Total & 18 & 36,7 & 16 & 32,7 & 15 & 30,6 & 49 & 100,0 \\
\hline
\end{tabular}


Tabla 3. Análisis morfotécnico de las BN1G de la UE4

\begin{tabular}{|c|c|c|c|c|c|c|}
\hline \multirow{3}{*}{ Criterios analíticos } & \multicolumn{4}{|c|}{ Facialidad BN1G } & \multirow{2}{*}{\multicolumn{2}{|c|}{$\begin{array}{c}\text { Total caras } \\
\text { talladas }\end{array}$}} \\
\hline & \multicolumn{2}{|c|}{ Unifacial } & \multicolumn{2}{|c|}{ Bifacial } & & \\
\hline & $\mathrm{N} .^{\circ}$ & $\%$ & N. ${ }^{\circ}$ & $\%$ & $\mathrm{~N} .^{\circ}$ & $\%$ \\
\hline \multicolumn{7}{|l|}{ Carácter centrípeto } \\
\hline $1 \mathrm{C}$ & 1 & 25,0 & 3 & 75,0 & 4 & 11,1 \\
\hline $2 \mathrm{C}$ & 2 & 50,0 & 2 & 50,0 & 4 & 11,1 \\
\hline $3 C$ & 8 & 66,7 & 4 & 33,3 & 12 & 33,3 \\
\hline $4 C$ & 9 & 56,3 & 7 & 43,8 & 16 & 44,4 \\
\hline Total & 20 & 55,6 & 16 & 44,4 & 36 & 100,0 \\
\hline \multicolumn{7}{|l|}{ Carácter de oblicuidad } \\
\hline Plano & 16 & 76,2 & 5 & 23,8 & 21 & 58,3 \\
\hline Semiplano & 0 & 0,0 & 5 & 100,0 & 5 & 13,9 \\
\hline Simple & 3 & 42,9 & 4 & 57,1 & 7 & 19,4 \\
\hline Semiabrupto & 1 & 33,3 & 2 & 66,7 & 3 & 8,3 \\
\hline Total & 20 & 55,6 & 16 & 44,4 & 36 & 100,0 \\
\hline \multicolumn{7}{|l|}{ Profundidad del retoque } \\
\hline Marginal & 2 & 40,0 & 3 & 60,0 & 5 & 13,9 \\
\hline Profundo & 4 & 66,7 & 2 & 33,3 & 6 & 16,7 \\
\hline Muy profundo & 6 & 54,5 & 5 & 45,5 & 11 & 30,6 \\
\hline Profundidad total & 8 & 57,1 & 6 & 42,9 & 14 & 38,9 \\
\hline Total & 20 & 55,6 & 16 & 44,4 & 36 & 100,0 \\
\hline \multicolumn{7}{|l|}{ Arista frontal } \\
\hline Convexa & 9 & 42,9 & 12 & 57,1 & 21 & 58,3 \\
\hline Recta & 11 & 73,3 & 4 & 26,7 & 15 & 41,7 \\
\hline Total & 20 & 55,6 & 16 & 44,4 & 36 & 100,0 \\
\hline \multicolumn{7}{|l|}{ Arista sagital } \\
\hline Recta & 8 & 61,5 & 5 & 38,5 & 13 & 36,1 \\
\hline Incurvada & 8 & 47,1 & 9 & 52,9 & 17 & 47,2 \\
\hline Sinuosa & 4 & 66,7 & 2 & 33,3 & 6 & 16,7 \\
\hline Total & 20 & 55,6 & 16 & 44,4 & 36 & 100,0 \\
\hline \multicolumn{7}{|l|}{ Simetría arista sagital } \\
\hline Simétrica & 8 & 88,9 & 1 & 11,1 & 9 & 25,0 \\
\hline Asimétrica & 12 & 44,4 & 15 & 55,6 & 27 & 75,0 \\
\hline Total & 20 & 55,6 & 16 & 44,4 & 36 & 100,0 \\
\hline
\end{tabular}

Las BN1GC están representadas en la UE2 tan sólo por un bifaz, caracterizado por el extremo distal/medial de una pieza de talla bifacial, con retoques simples que cubren por completo ambas caras, arista frontal convexa y arista sagital sinuosa simétrica, presenta filos dobles diedros laterales, asociados a triedro distal, y, mientras que la UE4 ha proporcionado un canto de talla bifacial, con retoques simples de extracciones amplias que cubren por completo el extremo distal, presenta arista frontal recta y arista sagital incurvada asimétrica que da lugar a filo transversal diedro (Figura 6).

Cuantitativamente es evidente el predominio absoluto de BN1GE, respecto de las BN1GC, lo que nos indica que las estrategias de talla van encaminadas a la producción sistemática y exclusiva de BP, predominando los Temas Operativos Técnicos Indirectos (T.O.T.I.) frente a los Directos (T.O.T.D.).
Las características de las BN1GE son las siguientes:

- El carácter facial, que nos informa del número de caras talladas y que jerarquiza al resto, nos ha permitido identificar algunas diferencias a nivel diacrónico. Así, en la UE2 los sistemas de explotación unifaciales están compuestos por 29 piezas (66\%), los bifaciales con $10(22,7 \%)$, los multifaciales con $3(6,8 \%)$ y, por último, los trifaciales con 2 (4,5\%); en la UE3 los unifaciales están presentes con 18 objetos (58\%), seguidos de los bifaciales con $8(25,8 \%) y$, finalmente, los trifaciales con 5 (16,2\%); por último, en la UE4, los unifaciales cuentan con 20 objetos $(74,1 \%)$ y los bifaciales con 7 (25,9\%), lo que nos indica una drástica reducción cuantitativa y mayor simplicidad de los 


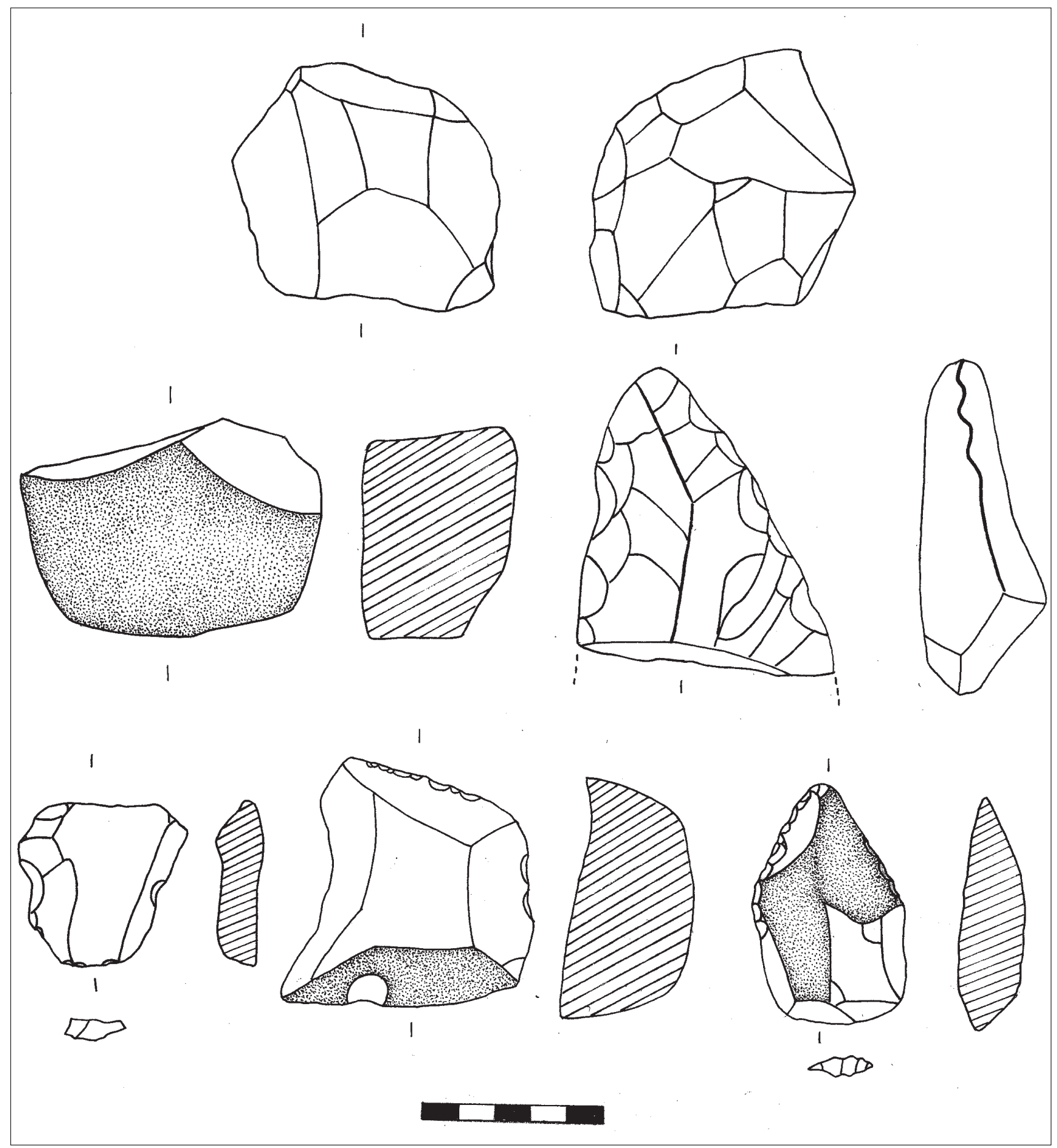

A Figura 6. Algetares. UE2. Multipolar, bifaz, muesca, retoque abupto y raedera.

sistemas de reducción lítica con respecto a las unidades estratigráficas anteriores.

- El carácter centrípeto, que nos informa del porcentaje de talla del perímetro, nos permite identificar como en la UE2 con un total de 63 superficies talladas, el criterio $4 \mathrm{C}$ supone casi el 50\% del registro; en la UE3 con 49 superficies talladas, el criterio 4C está presente en 30 de ellas, y en la UE4 con 36 superficies talladas, el criterio 4C se encuentra en 16 de ellas, por lo que es el mejor representado, pero en este caso le sigue muy de cerca el $3 \mathrm{C}$ con $1 / 3$ del conjunto. Estos datos confirman una notable diferencia de la UE4 con las UE2 y UE3, en las que observamos un alto grado de aprovechamiento y de explotación máxima de las BN1GE, mientras que en la UE4 tenemos nódulos menos agotados. 
- El carácter de oblicuidad, que marca la inclinación de las extracciones, nos permite comprobar cómo en la UE2 son las extracciones simples las predominantes, seguidas de las planas y las abruptas, mientras que en las UE3 y UE4, las extracciones planas marcan con diferencia el carácter de oblicuidad. Esta circunstancia nos pone en relación con la materia prima seleccionada, que permite una talla de carácter simple y plano, con una fractura limpia de la que se obtienen filos diedros activos, que no necesitan pasar a un segundo tiempo en el proceso de reducción lítica para su utilización.

- Del análisis de la profundidad de las extracciones de todas las UE, se observa el dominio del carácter total, seguido del muy profundo o del profundo y finalmente el marginal. Este dato unido a los obtenidos en el análisis del carácter centrípeto nos confirma el alto grado de aprovechamiento de las BN1GE.
- En la UE2 las aristas frontales son en su mayoría convexas, seguidas muy de lejos de las formas rectas, mientras que en las UE3 y UE4 se reparten prácticamente al 50\% entre convexas y rectas.

- Las aristas sagitales de las UE2 y UE3 predominan las formas rectas seguidas de las incurvadas, mientras en la UE4 la forma dominante es la incurvada y en todos los casos de carácter asimétrico.

Las Bases Positivas (BP) (Tabla 4), son la Categoría Estructural mejor representada en las tres unidades. En la UE2, 32 objetos presentan fractura proximal completa, no conservándose el talón, lo mismo ocurre con 12 artefactos de la UE3 y 11 de la UE4; estos fragmentos de bases positivas (FBP) no formarán parte del análisis morfotécnico por la distorsión porcentual que supondría. Otras 13 de la UE2, 15 de la UE3 y 10 de la UE4, son bases positivas fracturadas (BPF), en las que sí es reconocible el talón, por lo que se incluyen

Tabla 4. Análisis morfotécnico de las BP

\begin{tabular}{|c|c|c|c|c|c|c|c|c|}
\hline \multirow{2}{*}{ Criterios analíticos } & \multicolumn{2}{|c|}{ UE2 } & \multicolumn{2}{|c|}{ UE3 } & \multicolumn{2}{|c|}{ UE4 } & \multicolumn{2}{|c|}{ Total } \\
\hline & $\mathrm{N} .^{\circ}$ & $\%$ & N. ${ }^{\circ}$ & $\%$ & $\mathrm{~N} .{ }^{\circ}$ & $\%$ & N. ${ }^{\circ}$ & $\%$ \\
\hline \multicolumn{9}{|l|}{ Cara ventral } \\
\hline Convexa & 11 & 16,2 & 12 & 17,1 & 7 & 12,3 & 30 & 15,4 \\
\hline Recta & 25 & 36,8 & 34 & 48,6 & 18 & 31,6 & 77 & 39,5 \\
\hline Cóncava & 32 & 47,1 & 21 & 30,0 & 19 & 33,3 & 72 & 36,9 \\
\hline Sinuosa & 0 & 0,0 & 3 & 4,3 & 13 & 22,8 & 16 & 8,2 \\
\hline Total & 68 & 100,0 & 70 & 100,0 & 57 & 100,0 & 195 & 100,0 \\
\hline \multicolumn{9}{|l|}{ Cara talonar } \\
\hline Cortical & 33 & 48,5 & 26 & 37,1 & 27 & 47,4 & 86 & 44,1 \\
\hline No cortical & 35 & 51,5 & 44 & 62,9 & 30 & 52,6 & 109 & 55,9 \\
\hline Total & 68 & 100,0 & 70 & 100,0 & 57 & 100,0 & 195 & 100,0 \\
\hline Convexo & 16 & 23,5 & 23 & 32,9 & 19 & 33,3 & 58 & 29,7 \\
\hline Recto & 46 & 67,6 & 44 & 62,9 & 29 & 50,9 & 119 & 61,0 \\
\hline Cóncavo & 5 & 7,4 & 3 & 4,3 & 7 & 12,3 & 15 & 7,7 \\
\hline Sinuoso & 1 & 1,5 & 0 & 0,0 & 2 & 3,5 & 3 & 1,5 \\
\hline Total & 68 & 100,0 & 70 & 100,0 & 57 & 100,0 & 195 & 100,0 \\
\hline No facetado & 34 & 50,0 & 25 & 35,7 & 27 & 47,7 & 86 & 44,1 \\
\hline Unifacetado & 32 & 47,1 & 41 & 58,6 & 29 & 50,9 & 102 & 52,3 \\
\hline Bifacetado & 2 & 2,9 & 4 & 5,7 & 1 & 1,8 & 7 & 3,6 \\
\hline Total & 68 & 100,0 & 70 & 100,0 & 57 & 100,0 & 195 & 100,0 \\
\hline Plataforma & 59 & 86,8 & 63 & 90,0 & 53 & 93,0 & 175 & 89,7 \\
\hline Lineal & 3 & 4,4 & 6 & 8,6 & 3 & 5,3 & 12 & 6,2 \\
\hline Puntiforme & 6 & 8,8 & 1 & 1,4 & 1 & 1,8 & 8 & 4,1 \\
\hline Total & 68 & 100,0 & 70 & 100,0 & 57 & 100,0 & 195 & 100,0 \\
\hline \multicolumn{9}{|l|}{ Corticalidad cara dorsal } \\
\hline $\mathrm{CO}$ & 24 & 35,3 & 19 & 27,1 & 13 & 22,8 & 56 & 28,7 \\
\hline CO/NCO & 17 & 25,0 & 15 & 21,4 & 14 & 24,6 & 46 & 23,6 \\
\hline $\mathrm{NCO} / \mathrm{CO}$ & 12 & 17,6 & 25 & 35,7 & 18 & 31,6 & 55 & 28,2 \\
\hline NCO & 15 & 22,1 & 11 & 15,7 & 12 & 21,1 & 38 & 19,5 \\
\hline Total & 68 & 100,0 & 70 & 100,0 & 57 & 100,0 & 195 & 100,0 \\
\hline
\end{tabular}


en el estudio. En total el índice de fracturación de las BP es del $45 \%$ en la UE2, 32,9\% en la UE3 y $30,9 \%$ en la UE4 (Figura 7).

Entre las características de las BP podemos destacar:

- La tipometría de las BP de la UE2 nos aporta unos valores medios de $58,8 \times 53,2 \times 24,3 \mathrm{~mm}$ y de $63,7 \times$
$56,9 \times 26,4 \mathrm{~mm}$ en la UE3, situándose en ambas unidades entre las categorías de pequeño y mediano formato, mientras que la UE4 con 67,7 x61,4 x 27,4 mm, se situaría en la categoría de formato medio. Se puede observar como los valores de longitud, anchura y espesor aumentan según profundizamos en los niveles arqueológicos.
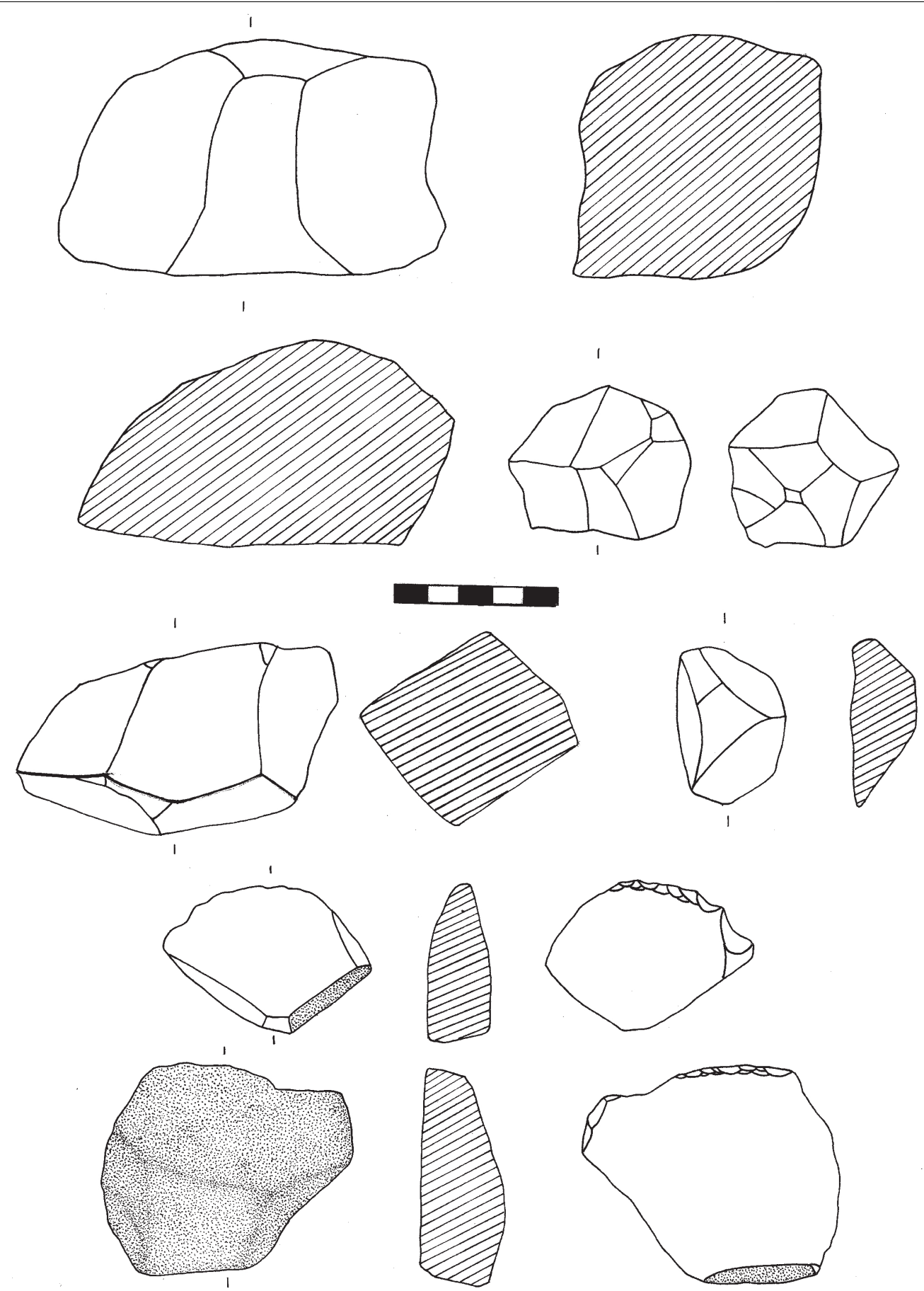

A FIGURA 7. Algetares. UE3. BN1GE: longitudinal (1), multipolar (2) y bipolar opuesto (3). BP: cortical (4). BN2G: raederas (5 y 6). 
- Las caras ventrales presentan un predominio de formas cóncavas en la UE2, lo que nos indica cierta flexibilidad de las piezas. Por el contrario, en la UE3, y como indicador de menor flexibilidad, predominan las formas rectas, mientras que en la UE4 hay un reparto equitativo de cóncavas y rectas.

- Las caras talonares han sido analizadas desde el grado de corticalidad, delineación, facetage, tipo y morfología. En la UE2 están representados casi al 50\% los talones corticales y no corticales, con formas rectas, no facetados y unifacetados al $50 \%$, en clara sintonía con la corticalidad y con un dominio absoluto del tipo plataforma en casi un 90\%; en la UE3, domina la cara talonar no cortical, recta, unifacetada, en plataforma y triangular; mientras que en la UE4, la cara talonar cortical y no cortical, recta o convexa, unifacetada y no facetada, en plataforma y triangulares, trapezoidales y rectangulares. Esta información hay que relacionarla con lo obtenido en el análisis de las BN1GE, ya que, el porcentaje de talones no corticales se relacionan con los sistemas de explotación más complejos y progresistas como los bipolares (opuesto y ortogonal), multipolares y centrípetos, mientras que las corticales se relacionan con los sistemas de explotación simples como el aleatorio y longitudinal.

- En las caras dorsales de la UE2 hay un dominio de BP corticales, como resultado de la elevada presencia de sistemas de explotación simples, mientras en las UE3 y UE4 hay mayor número de no cortical/cortical, aunque con un reparto equilibrado entre los cuatro criterios corticales. Dominan en las tres unidades las secciones longitudinales en segmento y las transversales en triángulo. El negativo de las extracciones es semiabrupto, seguido de los abruptos y simples en las UE2 y UE4 y abruptas seguidas de simples en la UE3, con un dominio de BP sin levantamientos en la UE2 como resultado del número de $\mathrm{BP}$ corticales, seguido de las que cuentan con menos de tres levantamientos en su cara dorsal en el resto de unidades. La forma del contorno es irregular en su mayoría, repartiéndose el resto entre cuadrangulares, rectangulares y trapezoidales.

Las Bases Negativas de Segunda Generación (BN2G) han sido divididas, según se correspondan con una secuencia de configuración (BN2GC) o de explotación (BN2GE).

Las BN2GC (Tabla 5), como BP que han sido se estudian utilizando los mismos criterios analíticos, en cuanto a cara ventral, cara talonar y cara dorsal, a lo que añadimos la asignación de orden y grupo al que pertenece según la tipología analítica (Laplace, 1972) (Figura 8).

Del estudio de la UE2 se desprende que la tipometría media de las BN2GC es de $49 \times 40,7 \times 20,1 \mathrm{~mm}$, lo que las sitúa en la categoría de pequeño formato, observándose una selección de las BP de menor tamaño para su configuración en herramientas de trabajo, mientras que la tipometría de las BN2GC de la UE3 es de $68,4 \times 66,5 \times 28 \mathrm{~mm}$, y de la UE4 es de $80,5 \times 68,5 \times 31,2 \mathrm{~mm}$, lo que las sitúa en la categoría de mediano formato.

En los criterios de selección de las BP para transformarlas en BN2GC de las UE2 y UE3, han primado las BP no corticales con caras ventrales rectas, talones rectos o convexos, lisos o corticales, no facetados o unifacetados, en plataforma triangular, con secciones longitudinales y transversales trapezoidales y triangulares, rechazando las secciones irregulares, para el contorno se ha preferido utilizar BP con forma triangular y trapezoidal, mientras que en la UE4 no se observa esa selección, ya que se utilizan BP con talones, secciones y contornos irregulares.

En cuanto a su clasificación por Orden y Grupo, en la UE2 se realiza una talla simple o sobreelevada para configurar 5 raederas (R1), 6 muescas (D21), 5 denticulados (D1, D2 y D3) y 2 raspadores (G11 y G12), así como una talla abrupta para 2 abruptos ( $A 1$ y $A 2$ ); también se encuentra representado en esta Categoria Estructural un hendedor sobre BP cortical/no cortical, con fractura completa del extremo proximal, por lo que carecemos de talón, cara ventral convexa, filo diedro en el extremo distal y retoques simples, marginales, inversos, continuos y rectos en el lateral izquierdo.

La UE3 ha permitido, únicamente, la documentación de talla simple o sobreelevada en la configuración de 1 raedera (R21), 3 muescas (D21), 8 denticulados (D1, D2, D21 y D32) y 2 raspadores (G32); constatándose los mismos tipos de talla en la UE4, en la configuración de 5 raederas (R11, R12 y D23), 3 muescas (D21), 3 denticulados (D2) y 1 raspador (G31). Igualmente, en la UE4 se ha documentado una herramienta de gran formato (bifaz), siendo sus medidas $14,9 \times 8,9 \times 5 \mathrm{~cm}$, realizado sobre BP no cortical, con grado de rodamiento medio, talla bifacial, con retoques simples de extracciones amplias que cubren por completo ambas caras, arista frontal convexa y arista sagital sinuosa simétrica, presenta filos dobles diedros laterales que aumentan el ángulo hacia la zona proximal, asociados a diedro distal, carece de la configuración final de los bordes para su regularización (que si aparecía en el bifaz procedente de TOTD de la UE2), por lo que su configuración se corresponde con una serie corta, aprovechando el talón de la BP sobre la que está configurado como punto de presión, por lo que la intervención sobre la BP está destinada a configurar su potencial de intervención y simetría (Figura 9).

Finalmente, en la UE4 tenemos presente 5 Bases Negativas de Segunda Generación de Explotación (BN2GE), de las cuales 4 son unifaciales ( 3 aleatorios no jerarquizados y 1 bipolar opuesto) y 1 bifacial que se corresponde con un sistema de explotación longitudinal, domina el criterio 4C en el carácter centrípeto, así como las extracciones planas en el de 
Tabla 5. Análisis morfotécnico de las BN2GC

\begin{tabular}{|c|c|c|c|c|c|c|c|c|}
\hline \multirow{2}{*}{ Criterios analíticos } & \multicolumn{2}{|c|}{ UE2 } & \multicolumn{2}{|c|}{ UE3 } & \multicolumn{2}{|c|}{ UE4 } & \multicolumn{2}{|c|}{ Total } \\
\hline & $\mathrm{N} .^{\circ}$ & $\%$ & N. ${ }^{\circ}$ & $\%$ & $\mathrm{~N} .{ }^{\circ}$ & $\%$ & N. ${ }^{\circ}$ & $\%$ \\
\hline \multicolumn{9}{|l|}{ Cara ventral } \\
\hline Convexa & 4 & 19,0 & 3 & 21,4 & 1 & 7,7 & 8 & 16,7 \\
\hline Recta & 12 & 57,1 & 6 & 42,9 & 8 & 61,5 & 26 & 54,2 \\
\hline Cóncava & 4 & 19,0 & 2 & 14,3 & 2 & 15,4 & 8 & 16,7 \\
\hline Sinuosa & 1 & 4,8 & 3 & 21,4 & 2 & 15,4 & 6 & 12,5 \\
\hline Total & 21 & 100,0 & 14 & 100,0 & 13 & 100,0 & 48 & 100,0 \\
\hline \multicolumn{9}{|l|}{ Cara talonar } \\
\hline Cortical & 8 & 38,1 & 5 & 35,7 & 4 & 30,8 & 17 & 35,4 \\
\hline No cortical & 8 & 38,1 & 7 & 50,0 & 4 & 30,8 & 19 & 39,6 \\
\hline No cortical & 5 & 23,8 & 2 & 14,3 & 5 & 38,5 & 12 & 25,0 \\
\hline Total & 21 & 100,0 & 14 & 100,0 & 13 & 100,0 & 48 & 100,0 \\
\hline Convexo & 3 & 18,8 & 4 & 33,3 & 3 & 37,5 & 10 & 27,8 \\
\hline Recto & 12 & 75,0 & 5 & 41,7 & 5 & 62,5 & 22 & 61,1 \\
\hline Cóncavo & 1 & 6,3 & 2 & 16,7 & 0 & 0,0 & 3 & 8,3 \\
\hline Sinuoso & 0 & 0,0 & 1 & 8,3 & 0 & 0,0 & 1 & 2,8 \\
\hline Total & 16 & 100,0 & 12 & 100,0 & 8 & 100,0 & 36 & 100,0 \\
\hline No facetado & 8 & 50,0 & 5 & 41,7 & 4 & 50,0 & 17 & 47,2 \\
\hline Unifacetado & 7 & 43,8 & 6 & 50,0 & 4 & 50,0 & 17 & 47,2 \\
\hline Bifacetado & 1 & 6,3 & 1 & 8,3 & 0 & 0,0 & 2 & 5,6 \\
\hline Total & 16 & 100,0 & 12 & 100,0 & 8 & 100,0 & 36 & 100,0 \\
\hline Plataforma & 14 & 87,5 & 11 & 91,7 & 6 & 75,0 & 31 & 86,1 \\
\hline Lineal & 1 & 6,3 & 0 & 0,0 & 2 & 25,0 & 3 & 8,3 \\
\hline Puntiforme & 1 & 6,3 & 1 & 8,3 & 0 & 0,0 & 2 & 5,6 \\
\hline Total & 16 & 100,0 & 12 & 100,0 & 8 & 100,0 & 36 & 100,0 \\
\hline \multicolumn{9}{|l|}{ Cara dorsal } \\
\hline $\mathrm{CO}$ & 5 & 23,8 & 4 & 28,5 & 4 & 30,8 & 13 & 27,1 \\
\hline $\mathrm{CO} / \mathrm{NCO}$ & 3 & 14,3 & 2 & 14,3 & 1 & 7,7 & 6 & 12,5 \\
\hline $\mathrm{NCO} / \mathrm{CO}$ & 3 & 14,3 & 5 & 35,7 & 0 & 0,0 & 8 & 16,7 \\
\hline $\mathrm{NCO}$ & 10 & 47,6 & 3 & 21,4 & 8 & 61,5 & 21 & 43,8 \\
\hline Total & 21 & 100,0 & 14 & 100,0 & 13 & 100,0 & 48 & 100,0 \\
\hline \multicolumn{9}{|l|}{ Orden simple y SE } \\
\hline Raederas & 5 & 23,8 & 1 & 7,1 & 5 & 38,5 & 11 & 22,9 \\
\hline Raspadores & 2 & 9,5 & 2 & 14,3 & 1 & 7,7 & 5 & 10,4 \\
\hline Denticulados & 5 & 23,8 & 8 & 57,1 & 3 & 23,1 & 6 & 33,3 \\
\hline Muescas & 6 & 28,6 & 3 & 21,4 & 3 & 23,1 & 12 & 25,0 \\
\hline \multicolumn{9}{|l|}{ Orden abruptos } \\
\hline Abruptos & 2 & 9,5 & 0 & 0,0 & 0 & 0,0 & 2 & 4,2 \\
\hline Hendedores & 1 & 4,8 & 0 & 0,0 & 0 & 0,0 & 1 & 2,1 \\
\hline Bifaces & 0 & 0,0 & 0 & 0,0 & 1 & 7,7 & 1 & 2,1 \\
\hline Total & 21 & 100,0 & 14 & 100,0 & 13 & 100,0 & 14 & 100,0 \\
\hline
\end{tabular}


LOS MODELOS DE REDUCCIÓN LITICA EN ALGETARES (ALGECIRAS, CÁDIZ) DURANTE EL MODO 2 Y SU CONTEXTUALIZACIÓN HISTÓRICA...
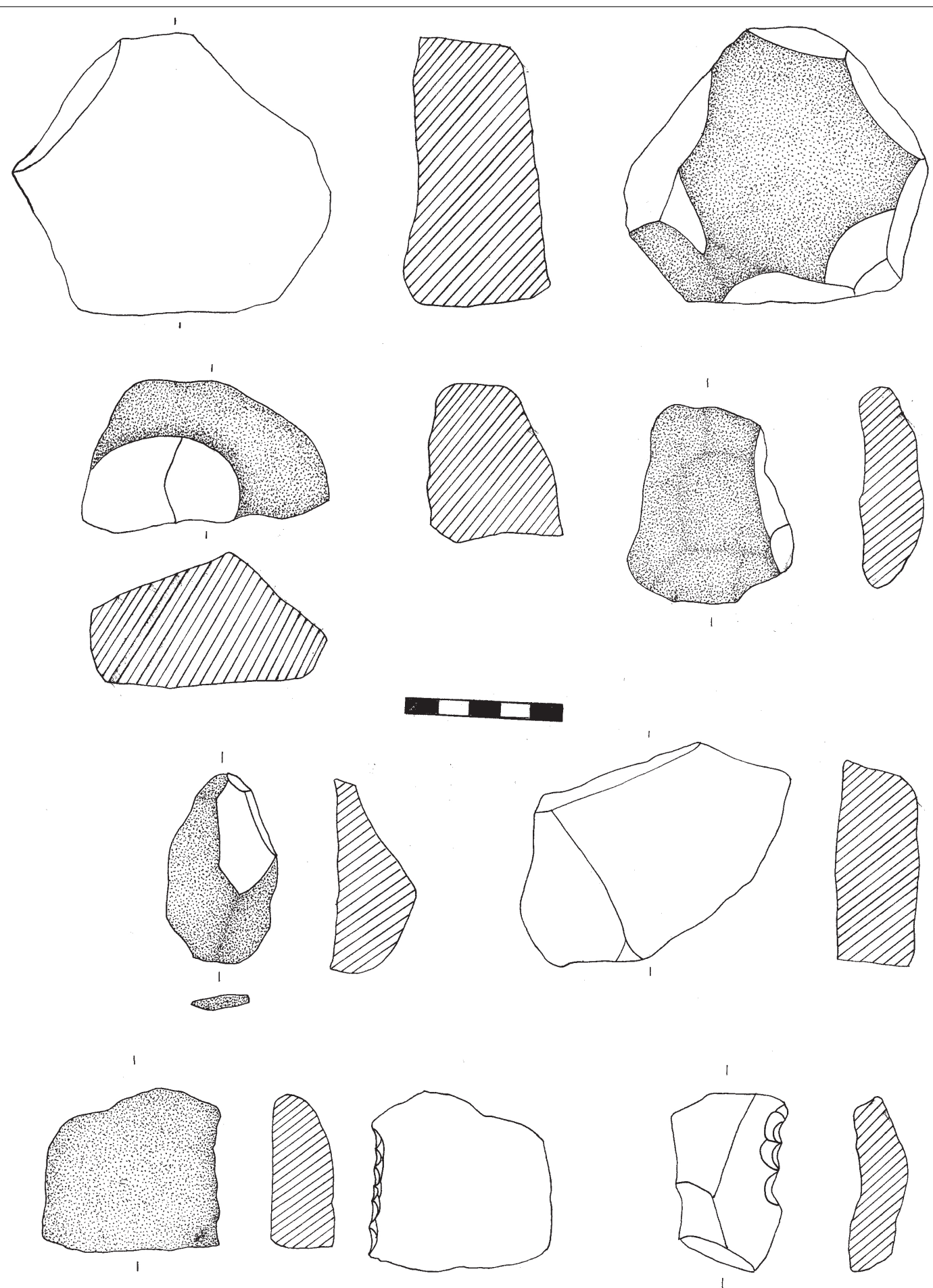

A Figura 8. Algetares. UE4. BN1GE: predeterminado parcial (1) y longitudinal (2). BP: cortical (3), cortical-no cortical (4), no cortical (5). BN2G: raedera (6) y denticulado (7). 


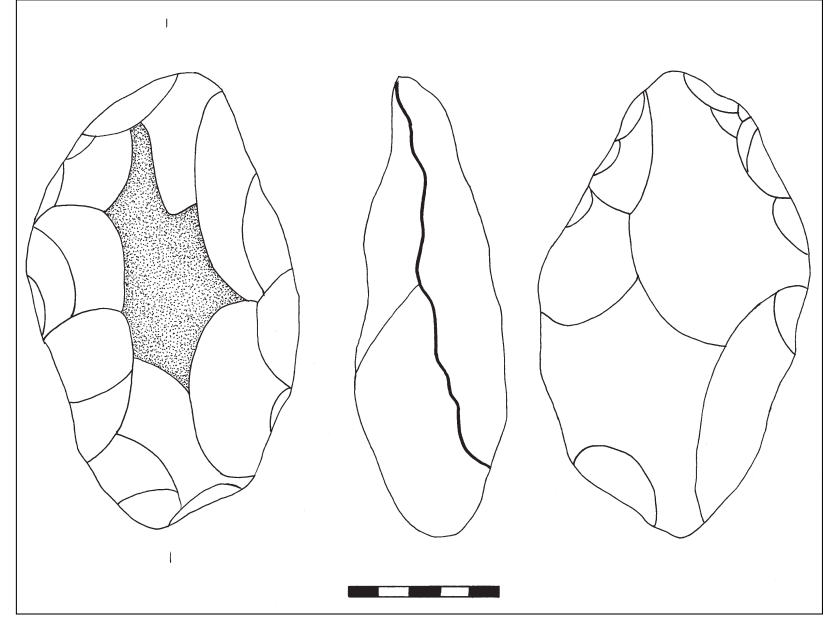

- Figura 9. Algetares. UE4. BN2G: bifaz. oblicuidad y los criterios totales y muy profundos en el carácter de profundidad de las extracciones. Constatamos 3 aristas frontales convexas, 2 cóncavas y 1 recta, así como 3 aristas sagitales rectas, 2 incurvadas y 1 sinuosa, todas ellas asimétricas.

La matriz morfogenética de la UE2 evidencia una gran variedad de TOTI, así como una mínima muestra de TOTD. Los sistemas de talla están representados por 20 longitudinales unifaciales (45,5\%), 7 aleatorios no jerarquizados con sistemas unifaciales, bifaciales y trifaciales (15,9\%), 4 bipolares ortogonales todos ellos bifaciales $(9,1 \%), 5$ multipolares $(11,4 \%), 1$ centrípeto sin preparación unifacial $(2,3 \%), 2$ centripetos con preparación parcial bifaciales $(4,5 \%)$ y 2 centrípetos predeterminados totales bifaciales (4,5\%) (Figura 10).

Se observa un claro predominio de los sistemas de explotación simples y poco elaborados, como son los longitu-

ALGETARES (ALGECIRAS) - U.E. 2

MATRIZ MORFOGENÉTICA

T.O.T.D.
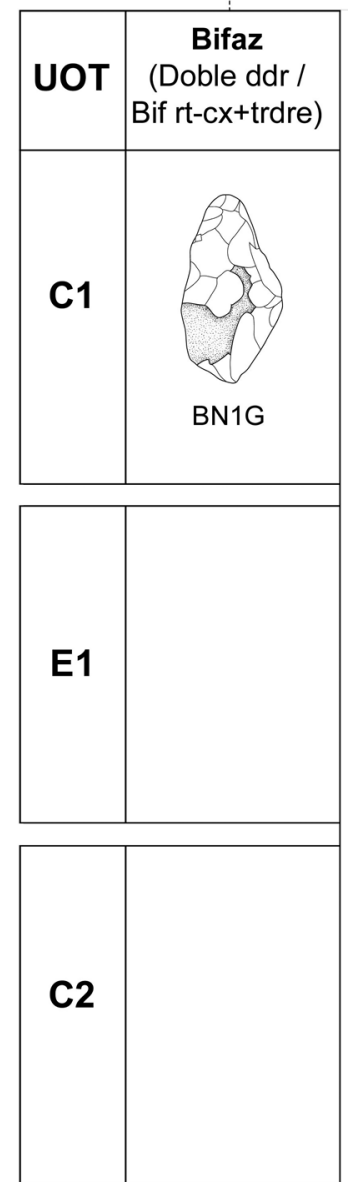

T.O.T.I.

\begin{tabular}{|l|c|c|c|c|c|}
\hline $\begin{array}{c}\text { Aleatorio } \\
\text { (Unif / Bif / Trif) }\end{array}$ & $\begin{array}{c}\text { Longitudinal } \\
\text { (Unif) }\end{array}$ & $\begin{array}{c}\text { Bipolar } \\
\text { opuesto } \\
\text { (Unif) }\end{array}$ & $\begin{array}{c}\text { Bipolar } \\
\text { ortogonal } \\
\text { (Bif) }\end{array}$ & $\begin{array}{c}\text { Centrípeto } \\
\text { (Unif / Bif) }\end{array}$ & $\begin{array}{c}\text { Multipolar } \\
\text { (Bif / Multif / Trif) }\end{array}$ \\
\hline & & & & & \\
& & & & & \\
\hline
\end{tabular}

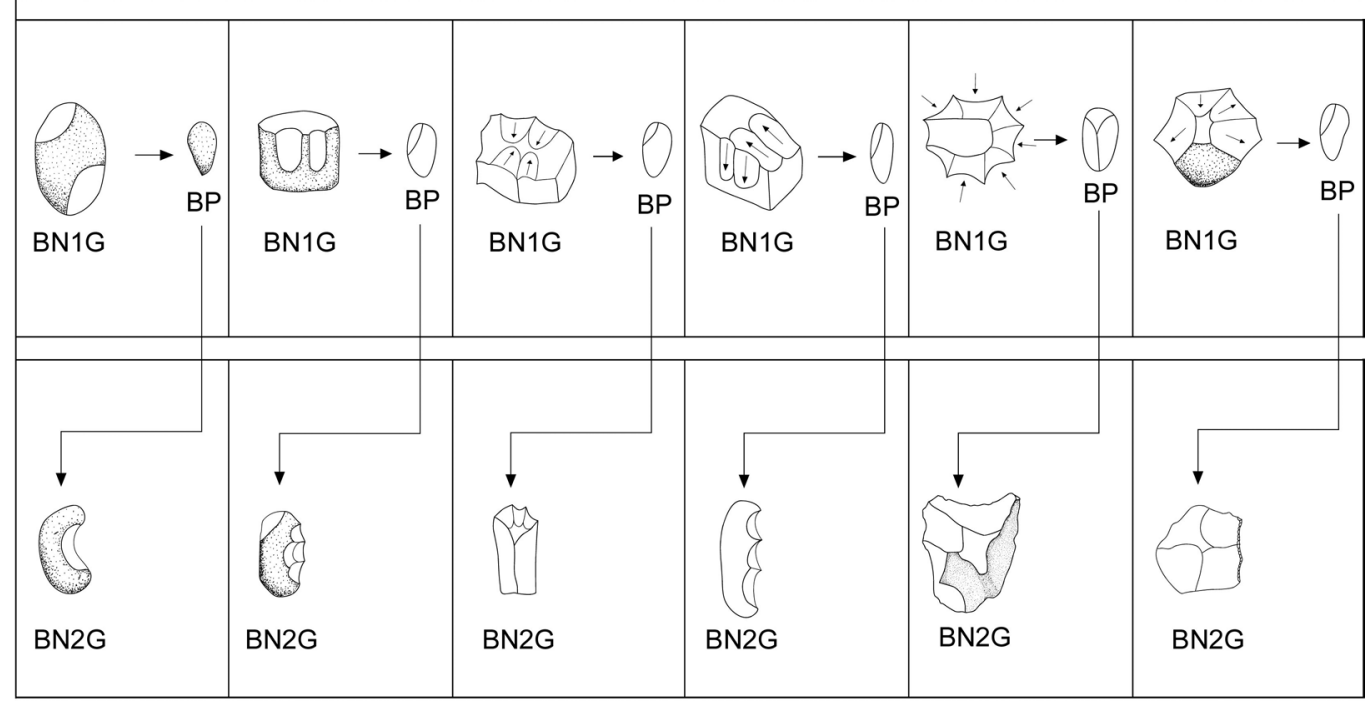

A Figura 10. Algetares. Matriz morfogenética de la UE2. 
dinales y aleatorios no jerarquizados, unifaciales en su mayoría, pero también junto a ello tenemos una representación de sistemas más complejos como los multipolares (5) o centrípetos sin preparación o preparación parcial (3), y los centripetos predeterminados totales (2) que requieren de sistemas de extracción plenamente estandarizados, para la obtención de BP procedentes de sistemas de explotación estandarizadas.
La matriz morfogenética de la UE3, al igual que ocurría en la anterior, se caracteriza por la variedad de TOTI y nula representación de TOTD. Los TOTI representados son 9 aleatorios unifaciales (29\%), 7 longitudinales unifaciales y 1 longitudinal bifacial (25,8\%), 6 bipolares ortogonales bifaciales $(19,4 \%), 5$ multipolares trifaciales $(16,1 \%), 2$ bipolares opuestos unifaciales $(6,5 \%)$ y 1 centrípeto predeterminado parcial bifacial (3,2\%) (Figura 11).

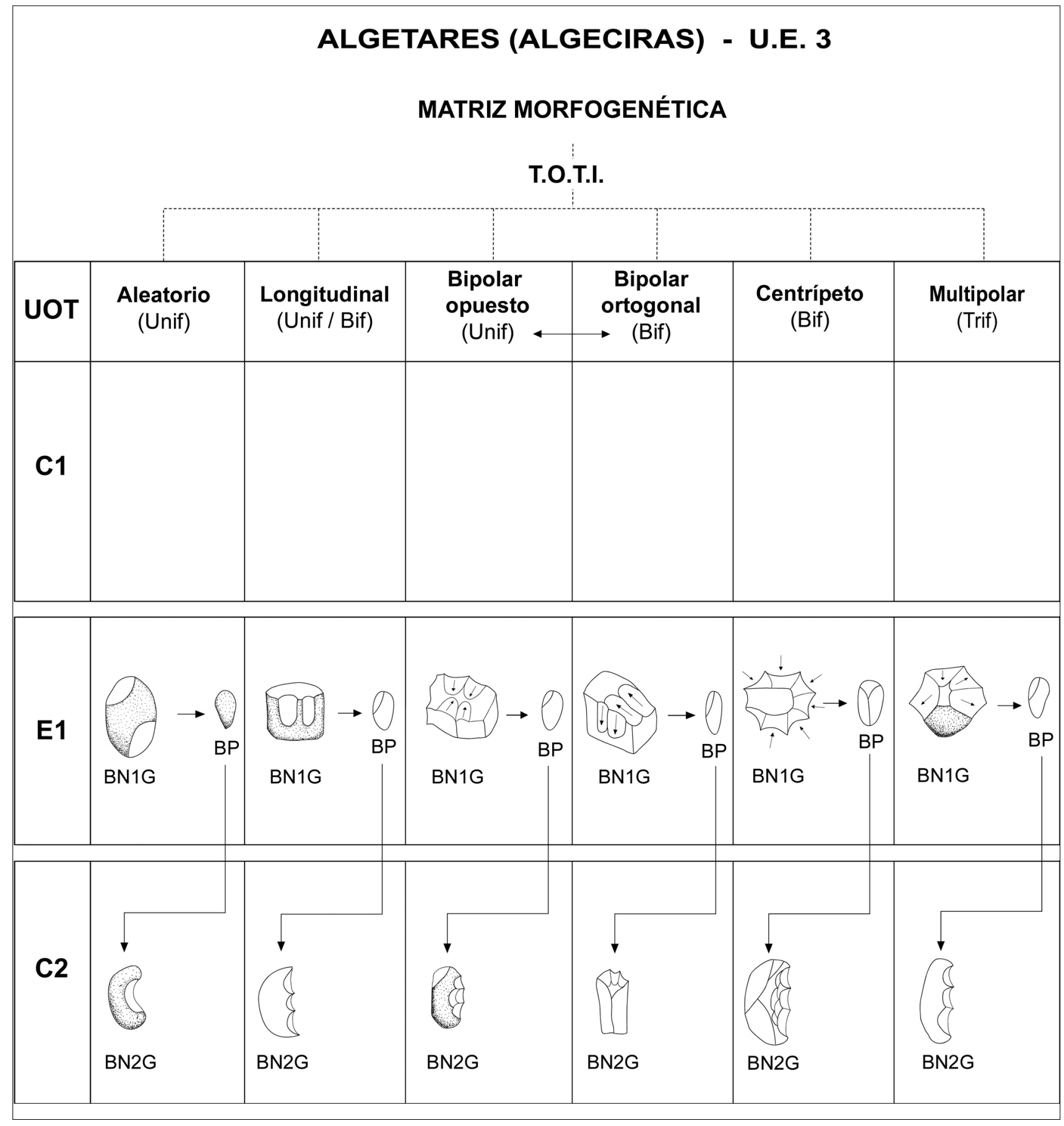

A Figura 11. Algetares. Matriz morfogenética de la UE3. 
Se evidencia un predominio de los sistemas de producción simples, representado por los aleatorios y longitudinales en su mayoría unifaciales y junto a ello cierto grado de preparación en los sistemas bifaciales y trifaciales, representados por los bipolares, multipolares y centripetos, aunque no llega a estar presente el tipo de BN1GE predeterminado total como ocurría en la UE2, ni aparecen los sistemas centripetos con porcentajes similares, disminuyendo notablemente en esta unidad.

La variabilidad de los TOTI representados en la matriz morfogenética de la UE4 es mayor de la de los TOTD. LOS TOTI documentados son 6 aleatorios, de los cuales 5 son unifaciales y 1 bifacial (22,2\%), 12 longitudinales unifaciales, de los que 9 son unipolares, 2 son unipolares masivos recurrentes y 1 es unipolar de preconfiguración de grandes instrumentos $(44,4 \%), 6$ bipolares, de los que 3 son opuestos unifaciales y otros 3 ortogonales bifaciales $(22,2 \%)$ y 3 centripetos predeterminados parciales bifaciales $(11,11 \%)$ (Figura 12).

En conclusión, podemos comentar como, a falta de dataciones absolutas, nos encontramos ante un conjunto muy homogéneo y que de manera global presenta una serie de sintonias que lo identifican claramente en una fase avanzada o progresiva del Modo Técnico 2, pero que a la vez, si analizamos las distintas unidades de manera individual, se observan una serie de identificadores que marcan diferencias notables internas, sobre todo si estudiamos por un lado las UE2 y UE3 más homogéneas y por otro la UE4, diferenciación ésta que también se observaba en el estudio geológico y geomorfológico. Así, en la UE4 se evidencia una drástica reducción cuantitativa y cualitativa de los sistemas de explotación, dominando los simples, representado por los aleatorios y longitudinales en su mayoría unifaciales y junto a ello un escaso grado de preparación en los sistemas bifaciales, de lo que se infiere un carácter menos progresivo del registro con $\mathrm{BN} 1 \mathrm{GE}$ menos agotadas, valores tipométricos medios de BP y BN2GC más elevados y escasa selección del tipo de BP para la configuración de BN2GC.

\section{EL SITIO DE ALGETARES (ALGECIRAS, CÁDIZ) Y SU CONTEXTUALIZACIÓN HISTÓRICA EN EL ÁMBITO DEL ESTRECHO DE GIBRALTAR}

Ya hemos comentado como la situación geográfica del sitio de Algetares lo convierten en un lugar inmejorable para comprender y explicar las relaciones como posible vía natural de comunicación entre los continentes europeos y africano, lugar este último donde se origina la humanidad.
Probablemente, el Estrecho de Gibraltar variaría entre unos 9-15 km durante las diferentes fases del Pleistoceno, dependiendo de la existencia o no de los períodos glaciares, $y$, por lo tanto, de la subida o bajada del nivel del mar; aunque quizás, la zona más propicia para cruzarlo se sitúe a unos $20 \mathrm{~km}$ al Oeste desde el punto que hemos señalado anteriormente, donde se localizarian probablemente pequeñas islas que reducirían los tramos marítimos. Pero el problema del Estrecho de Gibraltar no sólo atañe a la distancia que separa ambos continentes, sino también, al ser el Mediterráneo un mar deficitario, a las importantes corrientes marinas que se localizan en la zona.

Las primeras evidencias adscritas al modo 2 localizadas en el extremo Norte del continente africano se sitúan, por ejemplo, en la Unidad L de la Cantera de Thomas (Casablanca, Marruecos), donde la información bioestratigráfica y paleomagnética han permitido fecharla entre 1 y 0,78 m.a. (Raynal, et al., 2001). Este sistema técnico se constata en el continente africano hasta fechas próximas a 200 ka en sitios tales como Sidi Abderramán (Casablanca, Marruecos) (Figura 13).

Hasta la fecha, las primeras ocupaciones humanas localizadas en el Campo de Gibraltar se remontan al modo 2, probablemente, a falta de las necesarias dataciones absolutas ${ }^{8}$ y a los estudios geomorfológicos de las distintas terrazas marinas localizadas en el entorno, a los OIS7 y OIS5, cuando ya en el vecino continente africano estaba plenamente desarrollado el modo 3. Los depósitos geológicos donde se han localizado estas evidencias materiales se identifican con distintas terrazas fluviales relacionadas con los principales ríos que vertebran la comarca, tales como el Palmones, Guadarranque, Guadiaro y Hozgarganta (Castañeda, coord., 2008), las terrazas marinas localizadas en las antiguas líneas de costa del Campo de Gibraltar (Castañeda, et al., 2008) y los depósitos aluviales.

La información paleoclimática del entorno del Estrecho de Gibraltar durante OIS 7 y OIS5 sigue siendo bastante deficiente. Así, tan sólo contamos con algunos registros arqueológicos continentales identificados en distintas cavidades del Peñón de Gibraltar (Finlayson y Giles, 1999) y algunos sondeos oceánicos (MD95-2042 y MD95-2043) (Sánchez Goñi y d'Errico, 2005), que han permitido comprobar como durante OIS5 se mantienen unas condiciones climáticas templadas parecidas a las actuales. Para 0IS6 no contamos con datos, pero si para el OIS4, donde se observa un recrudecimiento de las temperaturas, que repercutirá especialmente en la cobertura vegetal atendiendo a la secuencia polínica regional ${ }^{9}$ y en menor medida sobre las especies animales, donde los estudios de macrofauna no han

$\left.{ }^{8}\right)$ Hemos intentado realizar algunas dataciones absolutas pero no ha sido posible ante la escasa presencia de fauna fósil localizada.

(9) Los cambios observados en la vegetación deben ser contextualizados atendiendo a los condicionantes medioambientales localizados en el extremo Sur de la Península lbérica (orografia, proximidad/distancia al mar, altitud/latitud, pluviosidad,...), que favorecen y determinan el desarrollo de áreas refugios de algunas especies vegetales características, tal como ocurre en la actualidad, de un clima más riguroso. 


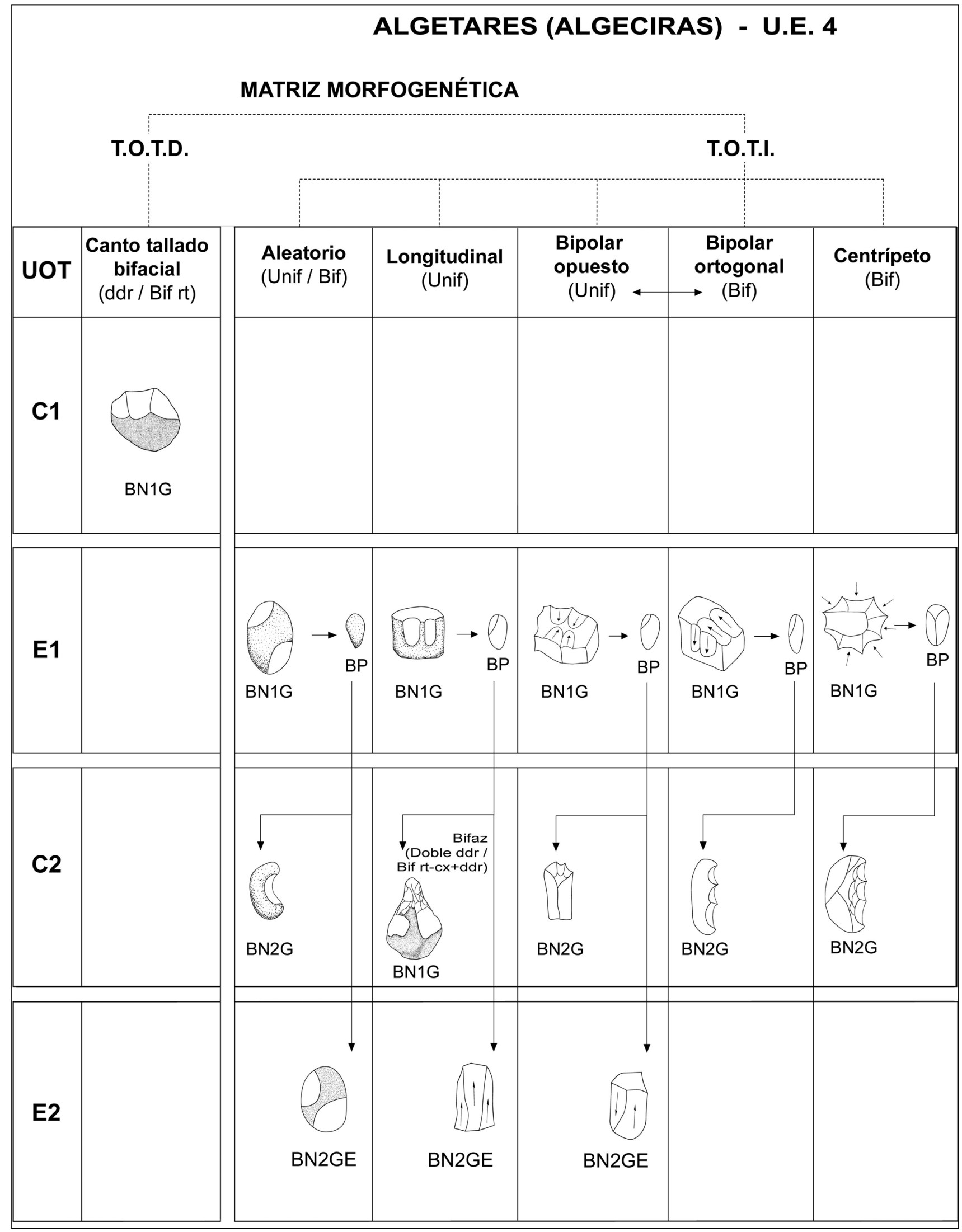

A Figura 12. Algetares. Matriz morfogenética de la UE4. 


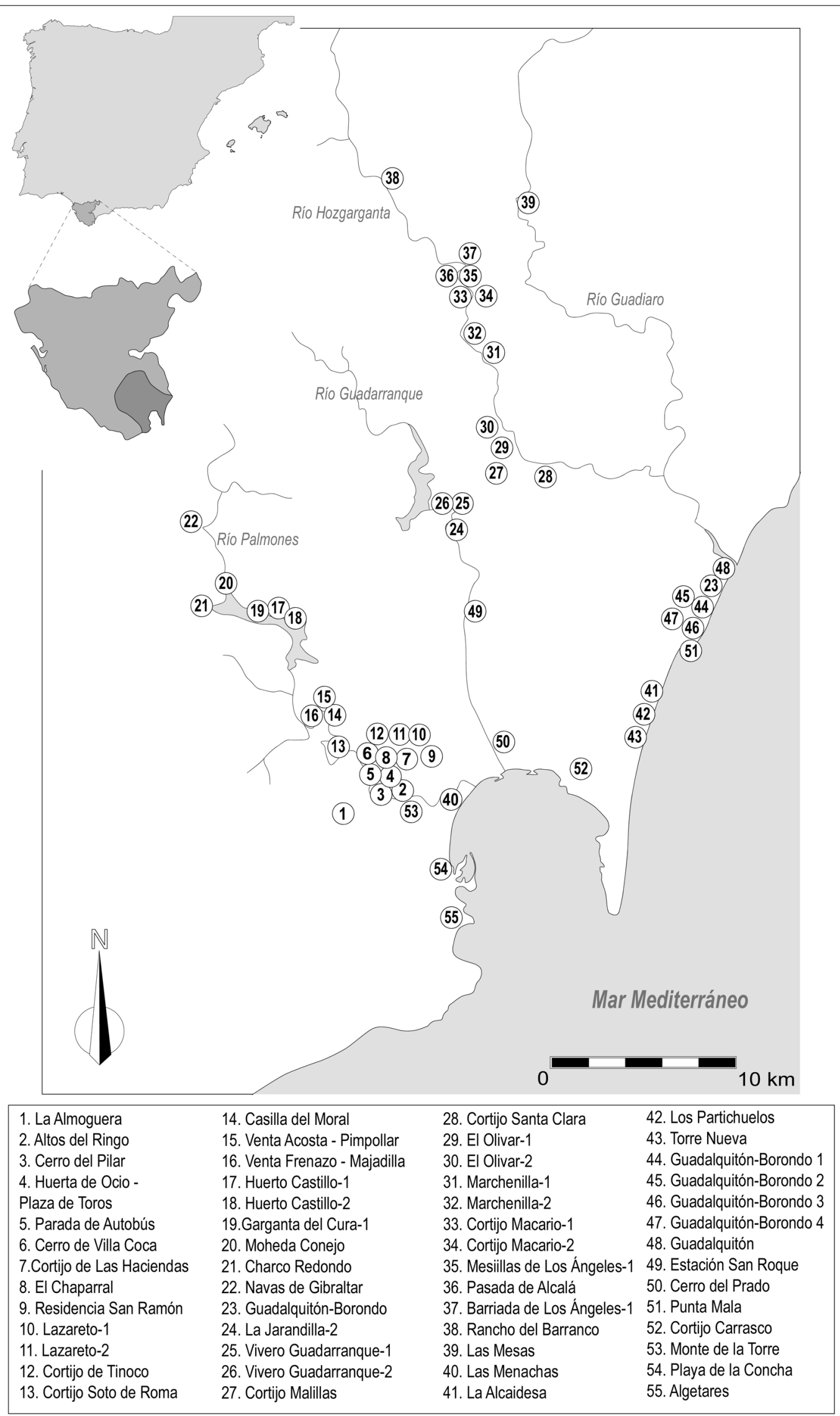

A Figura 13. Localización geográfica de los sitios pertenecientes al modo 2 en el Campo de Gibraltar. 
confirmado la presencia de "fauna de clima frío", aunque sí sobre la microfauna, más susceptibles a las variaciones paleoecológicas. Este hecho permite comprobar como los periodos glaciales tuvieron una incidencia menor sobre los ecosistemas atlántico-mediterráneos del ámbito del Estrecho de Gibraltar, los cuales no fueron modificados definitivamente, a diferencia de lo que ocurrió en latitudes más elevadas.

A partir del registro arqueológico, podemos comprobar como los lugares idóneos para la vida de estas primeras ocupaciones humanas se relacionan con los principales ríos que vertebran la comarca del Campo de Gibraltar (Palmones, Guadarranque, Guadiaro y Hozgarganta), los cuales deben ser explicados en un contexto dinámico-dialéctico espaciotemporal. Estos sitios les proporcionan agua dulce necesaria para la subsistencia; son unos lugares inmejorables para localizar, obtener y consumir carne, como consecuencia de la concentración de fauna que se acercaba a estos sitios para abrevar; y son una fuente inagotable de materias primas necesarias para la fabricación de sus herramientas de trabajo. Igualmente, los valles fluviales se convertirán en vías naturales de comunicación que permiten la relación de diferentes espacios geográficos (costa, valle y montaña). Por todo ello, los ambientes fluviales ofrecen unos recursos variados al localizarse en ambientes ecológicos diversificados, acentuándose esta circunstancia en el caso del ámbito del Estrecho de Gibraltar con el dominio de unas condiciones climáticas templadas durante buena parte del Pleistoceno (Figura 14).

El estudio de las diferentes terrazas fluviales localizadas en los principales ríos que vertebran el Campo de Gibraltar ha permitido la obtención de una información diacrónica, que unido a los datos procedentes del registro arqueológico nos ha permitido identificar, por ejemplo, para el río Palmones (Castañeda, coord., 2008) dos momentos históricos para el modo 2, que por comparación con otros ríos del entorno que presentan una secuencia más completa, como el Almodóvar (Hernaiz, et al., 1991a) o el Barbate (Hernaiz, et al., 1991b), se corresponderían con un Pleistoceno Medio.

Estos sitios arqueológicos localizados en las proximidades de los principales cursos fluviales del Campo de Gibraltar deben relacionarse con distintas ocupaciones puntuales y con una posición secundaria de los mismos como consecuencia de los flujos hidráulicos, que han permitido la conservación de éstos en lugares concretos (terrazas fluviales) (Torre Sainz, 2001). Pero como es lógico, la formación de estos sitios no solamente presenta un carácter posdeposicional, sino también antrópico.

Las materias primas seleccionadas y empleadas en la fabricación de las herramientas de trabajo de ambos momentos históricos se corresponden mayoritariamente con la arenisca; aumentando el porcentaje de distintos tipos de sílex, aunque en proporciones ínfimas, en los momentos más recientes. Su procedencia es de tipo local como consecuencia no sólo de su abundancia en el río Palmones, sino también por las características relacionadas con esta roca, donde no se emplea cualquier tipo de arenisca, sino aquellas más cementadas (por sílice fundamentalmente) y compactas (donde el tamaño del grano no influye), que ante los procesos de fracturación ofrecen unos filos diedros activos utilizados como herramientas de trabajo. Igualmente, la procedencia local de estas materias primas también viene constatada debido a los importantes volúmenes y pesos de las bases naturales seleccionadas, en comparación con épocas posteriores.

La gestión de las materias primas presenta algunas diferencias a nivel diacrónico. Así, los sitios localizados en las terrazas fluviales más elevadas (+ 42-33 $\mathrm{m})\left(\mathrm{T}_{3}\right)$, y por lo tanto con una cronología más antiguas, están caracterizados por unos patrones de explotación sencillo representados por el dominio de una talla aleatoria no jerarquizada, longitudinal y bipolar ortogonal. Por el contrario, en las terrazas medias (+32-15 m) $\left(T_{2}\right)$ se comienza a observar un paulatino aumento de un esquema racional y unas estrategias de talla más compleja (multipolar y centrípeto), frente a la más simple, aunque estas últimas siguen manteniendo unos porcentajes elevados.

Los patrones de estandarización también determinan las $\mathrm{BP}$, donde se constatan los diversos momentos del proceso de talla. Sus características, en correlación con las estrategias de explotación sencillas dominantes, también se observan en las plataformas de percusión identificadas, principalmente lisas y corticales.

Los restos arqueológicos localizados en estos sitios confirman una forma de vida depredadora, donde se documentan herramientas de trabajo relacionadas con la caza y el despiece de animales (bifaces, hendedores, triédros, cantos tallados,...), y otras actividades relacionadas con el trabajo de las pieles, la madera,... (raederas, muescas, denticulados,...). Junto a ello, debemos recordar como nos encontramos ante grupos que también practican las técnicas de recolección de alimentos de origen vegetal, que seguramente, y a falta de los estudios arqueobotánicos, tendrian un papel destacado en estas sociedades que habitaron en el ámbito del Estrecho de Gibraltar, dominado por unas condiciones climáticas templadas, que favorecería el desarrollo de una diversidad importante de distintos recursos vegetales estacionales.

A raíz de los estudios geomorfológicos, petrológicos y tecnológicos de las evidencias materiales localizas en las distintas UE del sitio de Algetares (Algeciras, Cádiz), éste podria relacionarse desde una perspectiva cronoestratigráfica sincrónico con la terraza media $\left(\mathrm{T}_{2}\right)$ del río Palmones, en una fase avanzada o progresiva del modo técnico 2. Asi, su registro litotécnico se caracteriza por la selección de unas materias primas en areniscas de carácter local y bien 


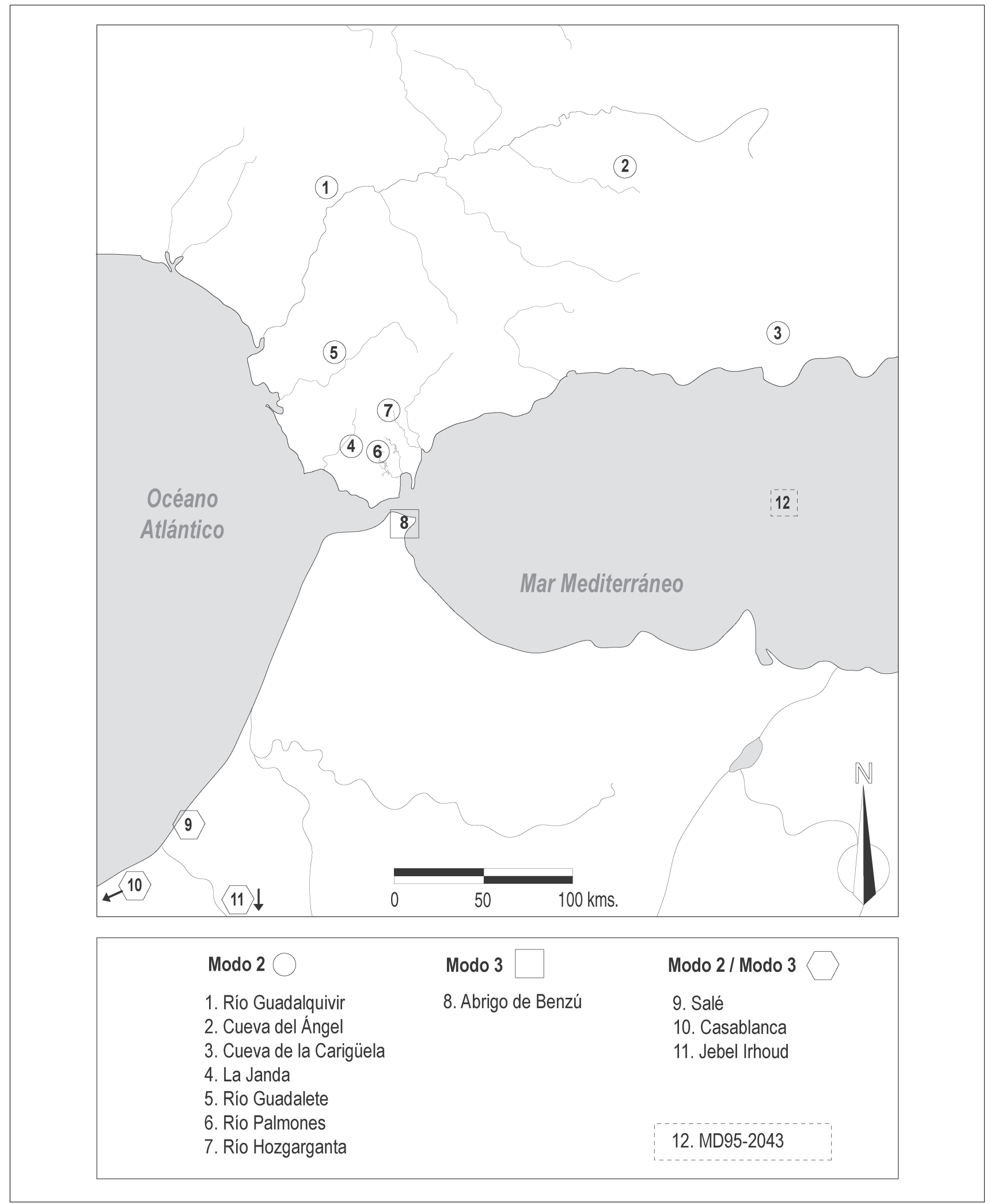

A Figura 14. El ámbito del Estrecho de Gibraltar entre $500 \mathrm{Ka} \mathrm{y} 120 \mathrm{Ka}$.

cementadas, y por la escasa representación de útiles de gran formato, presentes tan sólo en las UE2 y UE4, posiblemente relacionado con la fragmentación de la cadena operativa lí- tica, así como por el gran número de objetos que pertenecen a la categoría de pequeño y mediano formato, cuya tipometría media aumenta según descendemos de la UE2 a la UE4. 
Dominan en la UE4 los sistemas de explotación simples y poco elaborados como son los longitudinales y aleatorios no jerarquizados, pero también, junto a ello, se aprecia cierto grado de preparación en la UE3, representados por los bipolares y una representación de sistemas más complejos en la UE2 como los multipolares o centrípetos.

Tal como comentábamos con anterioridad, los valles fluviales no sólo serán lugares idóneos para la vida de este tipo de sociedades, sino también vías naturales de comunicación que relacionan diversos espacios geográficos (costa, valle y montaña). Así, por ejemplo, el río Palmones (Castañeda, coord., 2008) favoreció una comunicación perfecta con los principales ámbitos fluviales localizados en la banda atlántica de Cádiz durante el modo 2 (Ramos, coord., 2008), especialmente los relacionados con los ríos Barbate y Almodóvar (Castañeda, 2008), Guadalete (Giles, et al., 1993; Santiago, et al., 2001) y Guadalquivir (Vallespí, 1992, 2006). Por otra parte, los ríos Guadiaro y Hozgarganta permitirán la comunicación de diversos espacios geográficos (costa, valle y montaña), especialmente el relacionado con el área más occidental de sierras Subbéticas (Serranía de Ronda).

Las primeras ocupaciones humanas de la serranía de Ronda y su entorno inmediato se remontan a finales del modo 2 a inicios de lo que probablemente significó el subestadio 5e (130-122 ka), y deben relacionarse con una serie de cambios a nivel antropológico, social e histórico, y con un calentamiento global generalizado. Las bases arqueológicas de las que partimos para constatar este hecho se relacionan con una nueva ordenación social de territorio, donde se ocupan por primera vez las zonas de montañas, y a los cambios observados en la selección de las materias primas, con un aumento significativo de los diversos tipos de sílex en las herramientas de trabajo realizadas sobre BP, y en los procesos técnicos de fabricación de las mismas, con el dominio de unos esquemas racionales y unas estrategias complejas en la gestión de las materias primas (centrípeto), una disminución de los TOTD (bifaces, triédros y cantos tallados), y un aumento significativo de las herramientas de trabajo sobre $B P_{1} \ldots$
A partir de este momento histórico (OIS5), no solamente se ocuparán los biotopos relacionados con los principales ámbitos fluviales del Campo de Gibraltar (ríos Palmones, Guadiaro, Hozgarganta,...) (Castañeda, coord., 2008) en sus tramos asociados a la costa y el valle, sino también a partir de éstos las zonas de montaña (Giles, et al., 2003), aunque siempre relacionados con los valles fluviales y sus zonas limítrofes (incluidos probablemente los medios kársticos vinculados a ellos), no habitando aún las zonas más agrestes.

El registro arqueológico con el que contamos para comprender históricamente esta primera ocupación humana de la serranía de Ronda sigue siendo bastante deficiente. Sin embargo, este hecho empieza a definirse en el extremo Sur de la Península lbérica gracias al registro material y a las cronologías absolutas obtenidas en las primeras estribaciones de la Sierra Subbética, en sitios tales como la cueva del Ángel (Lucena, Córdoba) (Botella, et al., 2006), situada a 620 m.s.n.m., que ha ofrecido una cronología de $121 \pm 10$ ka por U/Th (OIS5) para las últimas etapas del modo 2; o la localizada en la cueva de la Carihuela (Piñar, Granada), en un farallón rocoso en plena Sierra de Harana a 1000 m.s.n.m, donde su nivel basal adscrito también a las últimas etapas del modo 2 presenta unas dataciones entre 146 y 117 ka (Vega Toscano, $1988,1997)$. Igualmente, en este contexto podriamos mencionar, aunque carezcan actualmente de dataciones absolutas, pero si con buenos registros faunísticos, los sitios de la Solana del Zamborino (Fonelas, Granada) (Botella, et al., 1976; Martínez y López Reyes, 2001) y, un poco anterior a este último, Cueva Horá (Darro, Granada) (Botella, et al., 1983).

Estos cambios históricos, que se documentan arqueológicamente con la nueva ordenación social del territorio, donde se empieza a constatar una frecuentación de los diferentes biotopos (costa, valle y montaña) por medio del nomadismo a finales del modo 2 y las modificaciones observadas en los procesos de trabajo, nos permite avanzar una nueva realidad social y la adquisición de unos comportamientos que nos acercan a la forma de vida y de trabajo del Homo neanderthalensis clásico y del modo 3 en el Sur de la Península Ibérica.

\section{BIBLIOGRAFÍA}

Botella, D., Barroso, C., Riquelme, J. A., Abdessadok, S., Caparrós, M., Verdú, L., Monge, G., y García, J. A., 2006: "La Cueva del Ángel (Lucena, Córdoba), un yacimiento del pleistoceno medio y superior del sur de la Península Ibérica", Trabajos de Prehistoria 63, (2), 153-165.

Botella, M. C., Vera, J. A., Porta, J., Casas, J., Peña, J. A., Marquez, I., BeNITO, A., RuIZ, A., y DELGADO, M. T., 1976: "El yacimiento achelense de la Solana del Zamborino, Fonelas (Granada). Primera campaña de excavaciones", Cuadernos de Prehistoria, 1, 1-45.

Botella, M. C., Martínez, C., CÁrdenas, F., y Cañabate, M. J., 1983: "Las industrias paleolíticas de Cueva Horá (Darro, Granada). Avance al estudio técnico y tipológico", Antropología y Paleoecología Humana, 3, 13-48.
Carbonell, E., Diez, C. y Martin, A., 1987: "Análisis de la industria lítica del complejo Atapuerca (Burgos)". En Aguirre, E., Carbonell, E. y Bermudez de Castro, J. M. : El hombre fósil de lbeas y el pleistoceno de la Sierra de Atapuerca, 389-423.

Carbonell, E., Guilbaud, M. y Mora, R., 1983: "Utilización de la lógica analítica para el estudio de tecno-complejos a cantos tallados". Cahier Noir, 1, 3-64.

Carbonell, E., Marquez, B., Mosouera, M., Olle, A., Rodriguez, X. P., Sala, R. Y VergeS, J. M., 1997: "El modo 2 en Galería. Análisis de la industria lítica y sus procesos técnicos". En Carbonell, E., Rosas, A. y Diez, J.C. (eds.): Atapuerca: ocupaciones humanas y paleoecología del yacimiento de Galería, 299-352.

Carbonell, E., Rodriguez, X. P., Mosouera, M., Olle, A., Sala, R., Vaquero, M. Y VERGES, J. M., 2006: "El Sistema Lógico Analítico: una herramienta 
para el estudio de la tecnología prehistórica". Dialektikê. Cahiers de Typologie Analytique, Hommage a Georges Laplace, 44-62.

Carbonell, E., Rodriguez, X. P., Sala, R. y Vaquero, M., 1992: "New elements of the logical analytic system", Cahier Noir, 6, 3-59.

CAstañedA, V., 2001: "El estudio de las sociedades del Paleolítico en el Campo de Gibraltar. Una historia olvidada", Almoraima, 25, 3747.

CASTAÑEDA, V., coord., 2008: Las primeras ocupaciones humanas de los Barrios (Cádiz). El ejemplo proporcionado por el río Palmones, Servicio de Publicaciones de la Universidad de Cádiz e Istmo, Ayuntamiento de la Villa de Los Barrios, Cádiz.

CASTAÑEDA, V., 2008: "Las primeras sociedades del Paleolítico en la antigua laguna de La Janda. Comportamientos y modos de vida", Aljaranda, 69, 2-6.

Castañeda, V., Torres, F.L., Costela, Y., Pérez, L. y Bernal, J. M., 2008: "Las primeras ocupaciones humanas de San Roque. Las sociedades del Paleolítico", $L A C Y, 0$, Revista de estudios Sanroqueños, 9-24.

Castañeda, V., Herrero, N., Castañeda, A., Torres, F., y Mariscal, D., 2005a: "La intervención de urgencia realizada en las Parcelas 11 y 12 de la barriada de El Lazareto (Los Barrios, Cádiz). Una aproximación a las sociedades portadoras del tecnocomplejo Achelense o Modo 2". Anuario Arqueológico de Andalucía. 2002. II Actividades de Urgencia, 156-164, Consejería de Cultura. Junta de Andalucía.

Castañeda, V., Herrero, N., Castañeda, A., Torres, F., y Mariscal, D., 2205b: "Informe sobre la intervención de urgencia realizada en el Plan Parcial 7, Los Cuartillos (Los Barrios, Cádiz). Un ejemplo de las sociedades portadoras del tecnocomplejo Achelense o Modo 2", Anuario Arqueológico de Andalucía. 2002. II Actividades de Urgencia, 165-175, Consejeria de Cultura, Junta de Andalucia.

Castañeda, V., Torres, F., Pérez, L., Costela, Y., Jiménez-Camino, R., TomasSETII, J. M., Y BERNAL, J. M., e.p.: "El sitio Paleolítico de modo 2 de Algetares (Algeciras, Cádiz). Excavación arqueológica, descripción del depósito y análisis de la industria lítica y sus procesos técnicos". CAETARIA, 6.

CLARKE, D. L., 1984: Arqueología analítica. Ed. Bellaterra. Barcelona..

Dominguez-BelLA, S., 2008: "Materias primas transportadas por el río Palmones y arqueometria de las industris líticas". En Castañeda, V., (coordinador): Las primeras ocupaciones humanas de los Barrios (Cádiz). El ejemplo proporcionado por el río Palmones, 83-91, Servicio de Publicaciones de la Universidad de Cádiz e Istmo. Ayuntamiento de la Villa de Los Barrios. Cádiz.

Finlayson, C., Y Giles, F., 1999: "The southern Iberian Peninsula in the Late Pleistocene: Geographie, Ecology and Human occupation". En StringeR, C. B., BARTON, R. N. E. y FinLAYSON, J. C., eds.: Gibraltar and the Neanderthals 1848-1998, 139-154. Oxford.

GARCIA, J., 2005: Tecnología litica i variabilitat de les indústries del Plistocè mitjà i superior inicial del nord-est de la península lbèrica i sudest de Franca: nivel G de la Caune de L'Arago, la Selva i conques del Roselló, Ter i lacustre de Banyoles. Ph. D. Thesis, Universitat Rovira i Virgili de Tarragona (Dept. d'Historia, Història de L'Art i Geografia)..

GavalA, J., 1924: "Mapa Geológico de la provincia de Cádiz, escala 1:200.000". I.G.M.E. .

Giles, F., GutiérRez, J. M., Santiago, A., Mata, E., y Gracia, F. J., 1993: "Prospecciones arqueológicas y análisis geocronológicos y sedimentológicos en la cuenca del río Guadalete", Investigaciones Arqueológicas en Andalucía, 1985-1992, 211-218, Huelva.

Giles, F., Santiago, A., Aguilera, L., Gutiérrez, J. M., y Finlayson, C., 2003: "Paleolítico Inferior y Medio en la Sierra de Cádiz. Evidencias de grupos de cazadores-recolectores del Pleistoceno Medio y Superior", Almajar, 1, 8-35.

Hernaiz Huerta, P., Garcia De Domingo, A. y González lastra, J.: "Mapa y memoria de la Hoja no 1.074 (Tahivilla) a escala 1:50.000". Plan Magna. I.G.M.E. 1991a.

Hernaiz Huerta, P., Garcia De Domingo, A. y González Lastra, J., 1991b: "Mapa y memoria de la Hoja no 1.070 (Alcalá de los Gazules) a escala 1:50.000". Plan Magna. I.G.M.E.
Jiménez-Camino, R., Tomassetti, J. M., Ayala, S., Castañeda, V., Torres, F., Pérez, L., Costela, Y., Y Bernal, J. M., 2008: Memoria Final de la Actividad Arqueológica Preventiva realizada en el solar sito entre las calles Minerva y Ninfa (Yacimiento Paleolitico de Algetares), Inédito.

LAPLACE, G., 1972: "La typologie analythique et structurale: Base rationnelle d'etude des industries lithiques et osseouses. Banques des données archéologiques". Colloques nationaux du CNRS. Num. 932, 91-143.

Martín-AlgarRa, A., 1987: Evolución geológica alpina del contacto entre las zonas internas y las zonas externas de la Cordillera Bética. Tesis Doctoral Univ. Granada.

MArtinez, G., y López, V., 2001: "La Solana del Zamborino", Paleontología i Evolució, 23-30.

Mosouera, M., 1995: Procesos técnicos y variabilidad en la industria lítica del Pleistoceno medio de la Meseta: Sierra de Atapuerca, Torralba, Ambrona y Aridos. Tesis Doctoral. Universidad Complutense de Madrid.

Pendón, J., 1978: Sedimentación turbidítica en las unidades del Campo de Gibraltar. Tesis Doctoral. Secretariado de Publicaciones de la Univ, de Granada.

Ramos, J., coord., 2008: Memoria del Proyecto de Investigación "La ocupación prehistórica de la campiña litoral y banda atlántica de Cádiz". Arqueología Monografias, Junta de Andalucía, Sevilla.

Raynal, J. P., SBiHI AlaOUI, F .Z., GeRAads, D., Magota, L., y MoHI, A., 2001: "The earliest occupation of North-Africa: the Moroccan perspective", Quaternary International, 75, 65-75.

RODRIGUEZ, X. P., 1997: Los sistemas técnicos de producción lítica del Pleistoceno Inferior y Medio de la Península Ibérica: variabilidad tecnológica entre yacimientos del noreste y de la Sierra de Atapuerca. Ph. D. Thesis, Universitat Rovira i Virgili (Dept. d'Historia i Geografia).

RUIZ-REIG, P., 1994: Mapa y memoria de la Hoja n 87 (Algeciras) a escala 1:200.000. I.G.M.E.

SÁnCHEZ GoÑI, M. F., Y D'ERRICO, F., 2005: "La historia de la vegetación y el clima del último ciclo climático (OIS5-OIS1, 140.000-10.000 años BP) en la Península lbérica y su posible impacto sobre los grupos paleolíticos". Montes, R., Y LACERAS, J. A., coord.: Neandertales Cantábricos, Estado de la Cuestión. Monografías, 20, 115129. Museo Nacional y Centro de Investigaciones de Altamira. Santander.

Santiago, A., GutiérRez, J. M., Giles, F., MatA, E., y Aguilera, L., 2001: "El registro arqueológico de los primeros grupos humanos en la comarca de Jerez de la Frontera y su contexto en el sur de la Península lbérica. Resultados de un proyecto de Investigación", Revista de Historia de Jerez, 7

TomassetTI, J. M., 2003a: "Primeras evidencias de Paleolítico Inferior en el Término Municipal de Algeciras (Cádiz)", Almoraima, 29, 13-32.

ToMASSETTI, J. M., 2003b: "Paleolítico Inferior en el Término Municipal de Algeciras (Cádiz): análisis arqueológico", Actas del I/ Congreso de Paleontología "Villa de Estepona". Paleoantropología y Prehistoria", Pliocénica, 3, 152-158.

TorRe SAINZ, I., 2001: "El impacto de los procesos fluviales en la formación de los yacimientos arqueológicos pleistocenos al aire libre: pautas de análisis experimental". Espacio, Tiempo y Forma, Serie I, Prehistoria y Arqueología, 14, 13-45.

ToRres ABRIL, F., 2008: "Aproximación a la geología de la cuenca fluvial del río Palmones". En Castañeda, V., (coordinador): Las primeras ocupaciones humanas de los Barrios (Cádiz). El ejemplo proporcionado por el río Palmones, 67-82, Servicio de Publicaciones de la Universidad de Cádiz e Istmo. Ayuntamiento de la Villa de Los Barrios. Cádiz.

Torres, F., Garcia-Diaz, M., Gómez-Arroouia, M. y Mariscal, D., 2002: "Aprovisionamiento de materias primas líticas en el territorio del Campo de Gibraltar durante la Prehistoria". ALMORAIMA 29,5969. 
LOS MODELOS DE REDUCCIÓN LITICA EN ALGETARES (ALGECIRAS, CÁDIZ) DURANTE EL MODO 2 Y SU CONTEXTUALIZACIÓN HISTÓRICA...

VALLESPI, E., 1992: "Las industrias achelense de Andalucia: ordenación y comentarios", SPAL, 1, 61-78.

VALLESPI, E., 2006: "El Bajo Guadalquivir en el comienzo de su historia humana. Investigaciones de proyectos 1985-1993 y tesis doctorales de 1993, 98 y 99 (nota informativa)", CAREL, 4.

Vega Toscano, L. G., Hoyos, M., Ruiz Bustos, A., y Laville, H., 1988: "La séquence de la grotte de la Carihuela (Piña, Grenada): Cronostrati- graphie et paléolécologie du Pléistocène supérieur au sud de la Péninsule lbérique", En L'Homme de Neandertal. Vol. 2 : I'Environnement, Université de Liége, 169-180.

Vega Toscano, L. G., Cosano, P., VILlar, A., Escarpa, O., y Rojas, T., 1997: "Las industrias de la interfase Pleistoceno Medio-Superior en la cueva de la Carihuela (Piñar, Granada)", II Congreso de Arqueología Peninsular. Vol. I: Paleolítico y Epipaleolítico, 105-119, Zamora. 